\title{
Use of Cone Beam Computed Tomography in Endodontics
}

\author{
William C. Scarfe, ${ }^{1}$ Martin D. Levin, ${ }^{2}$ David Gane, ${ }^{3}$ and Allan G. Farman ${ }^{1}$ \\ ${ }^{1}$ Division of Radiology and Imaging Science, Department of Surgical and Hospital Dentistry, \\ The University of Louisville School of Dentistry, 501 South Preston Street, Louisville, KY 40292, USA \\ ${ }^{2}$ Department of Endodontics, School of Dental Medicine, University of Pennsylvania, Philadelphia, PA 19103, USA \\ ${ }^{3}$ Kodak Dental Imaging/Practiceworks, 1765 The Exchange, Atlanta, GA 30339, USA
}

Correspondence should be addressed to William C. Scarfe, wcscar01@gwise.louisville.edu

Received 16 September 2009; Accepted 15 December 2009

Recommended by Eiichiro I. Ariji

Cone Beam Computed Tomography (CBCT) is a diagnostic imaging modality that provides high-quality, accurate threedimensional (3D) representations of the osseous elements of the maxillofacial skeleton. CBCT systems are available that provide small field of view images at low dose with sufficient spatial resolution for applications in endodontic diagnosis, treatment guidance, and posttreatment evaluation. This article provides a literature review and pictorial demonstration of CBCT as an imaging adjunct for endodontics.

Copyright (C) 2009 William C. Scarfe et al. This is an open access article distributed under the Creative Commons Attribution License, which permits unrestricted use, distribution, and reproduction in any medium, provided the original work is properly cited.

\section{Introduction}

Since Kells first reported the usefulness of visualizing a lead wire in a root canal on a "radiogram" in establishing the length of a root canal in $1899[1,2]$, radiography has been a pivotal tool in the practice of endodontics. Almost a century later, building on the pioneering efforts of those using conventional computed tomography (CT) and microCT, the introduction of maxillofacial CBCT in 1996 provided the first clinically practical technology demonstrating application of $3 \mathrm{D}$ imaging for endodontic considerations [3].

\section{Role of Imaging in Endodontics}

Radiography is essential to successful diagnosis of odontogenic and nonodontogenic pathoses, treatment of the pulp chamber and canals of the root of a compromised tooth via intracoronal access, biomechanical instrumentation, final canal obturation, and assessment of healing. Imaging serves at all stages in endodontics [4].

(1) Preoperative Assessment. Imaging achieves visualization of dental and alveolar hard tissue morphology and pathologic alterations to assist correct diagnosis. It provides information on the morphology of the tooth including location and number of canals, pulp chamber size and degree of calcification, root structure, direction and curvature, fractures, iatrogenic defects, and the extent of dental caries. The effects of periradicular and periapical disease can be determined, including the degree of root resorption and characteristics of periapical osteolysis. Larger lesions, only determined by imaging, may necessitate adjunctive surgical procedures in addition to conventional intracanal therapy. Diagnostic radiographs help predict the potential for complications, permit root fracture detection, and demonstrate periapical lesions.

(2) Intraoperative. During therapy two intraoral periapical images may be performed. The first is a "working" radiograph achieved by placement of a metallic file(s) into the root canal(s) to a length that approximates that of the root as radiological and anatomic root apexes are almost never coincident. This ensures that mechanical debridement of the intracanal contents extends to the apical terminus of the canal and that obturation is dense, homogeneous, and contained within the root canal system. In addition, prior to final obturation, a "final" or pre-condensation 
radiograph is made to assure proper fitting of the master cone.

(3) Postoperative. A "postoperative" radiograph immediately after root canal obturation is made to assess the sealing condensation and containment of the root canal filling material within the root canal system. In cases where periradicular healing is incomplete, it acts as a baseline for assessment of healing in the medium and potentially long term. Imaging is important in evaluating the results of previous therapy, delayed healing, evaluating potential obstacles to retreatment, as well as surgical considerations [5].

\section{Limitations of Conventional 2D Imaging}

Intraoral radiography is based on the transmission, attenuation, and recording of X-rays on an analog film or digital receptor, and requires optimized geometric configuration of the X-ray generator, tooth, and sensor to provide an accurate projection of the tooth. The image produced is a two-dimensional (2D) representation of a three-dimensional (3D) object. If any component of the imaging chain process is compromised, the resulting image may demonstrate exposure or geometric errors [6] and be suboptimal. 3D characteristics such as complex dental anatomy and surrounding structures can make interpretation of 2D "shadows" difficult and can contribute to nonhealing of endodontic cases.

Success in endodontics is assessed in healing of the periapical bone adjacent to obturated canals. Goldman et al. [7] showed that in evaluating healing of periapical lesions using 2D periapical radiographs there was only $47 \%$ agreement between six examiners. Goldman et al. [8] also reported that when those same examiners evaluated the same films at two different times, they only had 19\%-80\% agreement between the two evaluations.

\section{Cone Beam Computerized Tomography}

In fields of dentistry where $3 \mathrm{D}$ imaging is necessary, CBCT is considered by some to be the standard of care [9-14]. CBCT is accomplished by using a rotating gantry to which an Xray source and detector are fixed. A divergent pyramidal- or cone-shaped source of ionizing radiation is directed through the middle of the area of interest onto an area X-ray detector on the opposite side of the patient. The X-ray source and detector rotate around a fixed fulcrum within the region of interest (ROI). During the exposure sequence hundreds of planar projection images are acquired of the field of view (FOV) in an arc of at least $180^{\circ}$. In this single rotation, CBCT provides precise, essentially immediate and accurate $3 \mathrm{D}$ radiographic images. As $\mathrm{CBCT}$ exposure incorporates the entire FOV, only one rotational sequence of the gantry is necessary to acquire enough data for image reconstruction. CBCT is a complementary modality for specific applications rather than a replacement for $2 \mathrm{D}$ imaging modalities [9-13].
The Food and Drug Administration (FDA) approved the first CBCT unit for dental use in the United States in March 8, 2001-the NewTom DVT 9000 (Quantitative Radiology srl, Verona, Italy). FDA approval for three more CBCT units quickly followed in 2003 followed for the 3D Accuitomo, (J. Morita Mfg. Corp., Kyoto, Japan) in March 6, the i-CAT (Imaging Sciences International, Hatfield, PA) in October 2, and the CB MercuRay (Hitachi, Medical Corp., Kashiwa-shi, Chiba-ken, Japan) on October 20. Since 2003, a number of other CBCT units have been FDA approved in the United States, including the Kodak 9000 3D, (Carestream/Trophy, Marne-la-Vallée, France), which is currently the highest resolution unit (Table 1). Several additional units are in various stages of development, testing, or application for FDA approval.

4.1. Types of CBCT Equipment. CBCT systems can be categorized according to the orientation of the patient during image acquisition, the scan volume irradiated, or the clinical functionality.

Patient Positioning. Depending on the system employed, maxillofacial CBCT can be performed with the patient in three possible positions: (1) sitting, (2) standing, and (3) supine. Equipment that requires the patient to be supine has a larger physical footprint and may not be readily accessible for patients with physical disabilities. Standing units may not be able to be adjusted to a height to accommodate wheelchair bound patients. Seated units are the most comfortable; however fixed seats may not allow ready scanning of physically disabled or wheelchair bound patients. As scan times are often similar to or greater than those used with panoramic imaging, perhaps more important than patient orientation is the head restraint mechanism used.

Scan Volume. The dimensions of the FOV, or scan volume, are primarily dependent on the detector size and shape, beam projection geometry, and the ability to collimate the beam. The shape of the FOV can be either a cylinder or spherical (e.g., NewTom 3G). Collimation of the primary X-ray beam limits $\mathrm{x}$-radiation exposure to the region of interest (ROI). Field size limitation therefore ensures that an optimal FOV can be selected for each patient based on disease presentation and the region designated to be imaged. Based on available or selected scan volume height, the use of units can be designed as follows:

(1) localized region (also referred to as focused, small field or, limited field) —approximately $5 \mathrm{~cm}$ or less,

(2) single arch $-5 \mathrm{~cm}$ to $7 \mathrm{~cm}$,

(3) inter-arch $-7 \mathrm{~cm}$ to $10 \mathrm{~cm}$,

(4) maxillofacial $-10 \mathrm{~cm}$ to $15 \mathrm{~cm}$,

(5) craniofacial-greater than $15 \mathrm{~cm}$.

In general, the smaller the scan volume, the higher the spatial resolution of the image. As the earliest sign of periapical pathology is discontinuity in the lamina dura and widening 


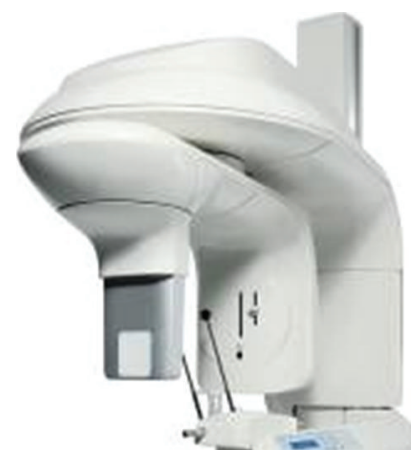

(a)

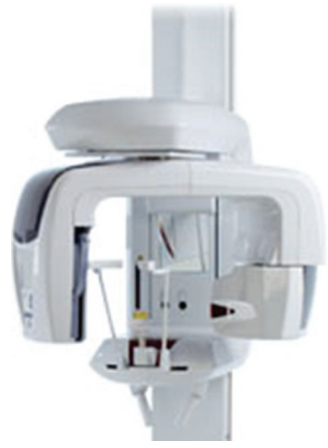

(b)

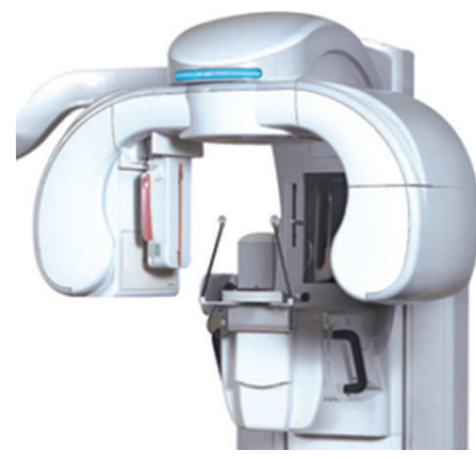

(c)

Figure 1: Examples of hybrid CBCT units. (a) KODAK Dental Imaging 9000 3D, (b) Veraviewepocs 3D, and (c) Picasso Trio.

of the periodontal ligament space, it is desirable that the optimal resolution of the any CBCT imaging system used in endodontics does not exceed $200 \mu \mathrm{m}$ - the average width of the periodontal ligament space. The 3D Accuitomo (J. Morita, Corporation, Kyoto, Japan) — the first of the small FOV systems-provided a resolution of $0.125 \mathrm{~mm}$. At the time of publication, nominal voxel resolution varies from $0.4 \mathrm{~mm}$ to $0.076 \mathrm{~mm}$.

Multimodality. Hybrid multimodal systems combine digital panoramic radiography with a relatively small-to mediumFOV CBCT system. This combination is now priced at a level similar to upper-level digital panoramic radiographic systems of the relatively recent past. Cost savings come from the fact that the cost of CBCT detectors is highly dependent on size. The ProMax 3D CBVT (Planmeca Oy, Helsinki, Finland) was the first to incorporate a small FOV 3D sensor to their ProMax digital panoramic line, which can be also be retrofitted to any of the prior ProMax digital models. Examples of other hybrid units are the Veraviewepocs 3D (J. Morita, Corporation, Kyoto, Japan), the Picasso Trio (Vatech/E. Woo Corporation, Korea), and the Kodak Dental Imaging 9000 DS (Kodak Dental Imaging/Practiceworks Atlanta, GA, USA) (Figure 1).

There are advantages beyond reduced capital costs to small FOV CBCT units for endodontic applications. First, a small FOV means that high-resolution images with a spatial resolution down to $0.076 \mathrm{~mm}$ isotropic voxel size can be achieved at very low exposure to ionizing radiation and without extensive reconstruction times that would be expected with larger FOV systems due to the greater file sizes to be processed. Second, a restricted FOV reduces the volume examined, and for which the practitioner is responsible to interpret. Small FOV systems concentrate on the dental arches or individual temporomandibular joints, the structures in which the average dentist is most familiar. There is less detail of the cranial cavity, paranasal sinuses, ear, and neck-structures less familiar to the average dentist. A small FOV CBCT system is undoubtedly too restrictive for maxillofacial surgeons who conduct craniofacial and orthognathic surgery or for complex implant/prosthetic situations where the jaws and both temporomandibular joints are best evaluated in toto rather than as individual components; however, third-party software is now available to "stitch" together adjacent small FOV images [15].

4.2. Radiation Dose Considerations. For a meaningful comparison of radiation risk, radiation exposures are converted to effective dose (E), measured in Sieverts (Sv). The Sv is a large unit; so in maxillofacial imaging milli- $\left[10^{-3} ; \mathrm{mSv}\right]$ or micro- $\left[10^{-6} ; \mu \mathrm{Sv}\right]$ Sieverts are reported. The radiation dose to specific tissues is measured, adjusted for the amount of that tissue in the field of view, and weighted based on radiation sensitivity of the tissue. The weighted tissue/organ doses are then summed to assess Effective Dose (E). Comparisons can be performed with respect to natural background radiation.

The tissues/organs used to calculate the effective dose are specified by the International Commission on Radiological Protection (ICRP). The organs used to calculate effective dose for imaging of the head include the bone marrow, thyroid, esophagus, skin, bone surface, salivary glands, brain, and "remainder" tissues [16]. Published effective doses for digital panoramic radiographs range from 5.5 to $22.0 \mu \mathrm{Sv}$ [17], while digital cephalometric radiographs have effective doses of 2.2 to $3.4 \mu \mathrm{Sv}$ [18]. This compares with an average annual effective dose from background radiation in the United States of about 3,000 $\mu \mathrm{Sv}(3.0 \mathrm{mSv})$.

There are a number of factors that will affect the radiation dose produced by a CBCT system: the imaging parameters used $(\mathrm{kVp}, \mathrm{mAs})$; pulsed beam versus continuous beam; amount, type, and shape of the beam filtration; the number of basis images dependent partly on use of $360^{\circ}$ or lesser rotations; and limitations on the size of the field of view. Factors such as beam quality and filtration are unique to a specific machine, while other factors, such as FOV, can sometimes be operator controlled. Typically, the smaller the field of view for a given system, the lower the radiation dose applied $[19,20]$. Since the effective dose is computed from a weighted summation of doses to various organs, removing some organs from the path of the X-ray beam 
TABLE 1: Current commercially available CBCT equipment.

\begin{tabular}{|c|c|c|}
\hline Unit & Model(s) & Manufacturer/Distributor \\
\hline Accuitomo & $\begin{array}{l}\text { 3D Accuitomo-XYZ Slice View } \\
\text { Tomograph/Veraviewpacs 3D }\end{array}$ & J. Morita Mfg. Corp., Kyoto, Japan \\
\hline Asahi Roentgen & PSR 9000N (Alphard 3030) & $\begin{array}{l}\text { Asahi Roentgen, Kyoto, Japan/Distributed by Belmont, } \\
\text { Somerset, NJ, USA }\end{array}$ \\
\hline Galileos & Galileos & Sirona Dental Systems, Charlotte, NC, USA \\
\hline GENDEX & CB 500 & $\begin{array}{l}\text { Imaging Sciences International, Hatfield, PA, } \\
\text { USA/Distributed by Gendex, Chicago, IL, USA }\end{array}$ \\
\hline Hitachi & CB MercuRay/CB Throne & Hitachi Medical Corp., Chiba-ken, Japan \\
\hline iCAT & Classic/Next Generation & Imaging Sciences International, Hatfield, PA, USA \\
\hline ILUMA & Ultra Cone Beam CT Scanner & $\begin{array}{l}\text { IMTEC Imaging Ardmore, OK, USA/Distributed by GE } \\
\text { Healthcare, Piscataway, NJ, USA }\end{array}$ \\
\hline $\mathrm{KaVo}$ & 3D eXam & $\begin{array}{l}\text { Imaging Sciences International, Hatfield, PA, } \\
\text { USA/Distributed by KaVo Dental Corp., Biberach, Germany }\end{array}$ \\
\hline KODAK & $90003 \mathrm{D} / 95003 \mathrm{D}$ & $\begin{array}{l}\text { KODAK Dental Systems, Carestream Health Rochester NY, } \\
\text { USA/Distributed exclusively in the USA by PracticeWorks, } \\
\text { Atlanta, GA, USA }\end{array}$ \\
\hline Newtom & 3G/NewTom VG & $\begin{array}{l}\text { QR, Inc. Verona, Italy/Dent-X Visionary Imaging, Elmsford, } \\
\text { NY, USA }\end{array}$ \\
\hline ORION & RCB-888 & Ritter Imaging GmbH, Ulm, Germany \\
\hline Picasso Series & Trio/Pro/Master & E-Woo Technology Co., Ltd/Vatech, Giheung-gu, Korea \\
\hline PreXion & $3 \mathrm{D}$ & PreXion, Inc. San Mateo, CA, USA \\
\hline Promax & $3 \mathrm{D}$ & Planmeca OY, Helsinki, FInland \\
\hline Ritter & Orion RCB-888 & Ritter Imaging GmbH, Ulm, Germany \\
\hline Scanora & Scanora 3D CBCT & SOREDEX, Tuusula, Finland \\
\hline SkyView & 3D Panoramic imager & My-Ray Dental Imaging, Cefla Dental Group, Imola, Italy \\
\hline Suni & $3 \mathrm{D}$ & Suni Corp., CA, USA \\
\hline TeraRecon & Fine Cube & $\begin{array}{l}\text { Yoshida Dental Mfg. Co. Ltd., Tokyo, Japan/Distributed by } \\
\text { TeraRecon, Inc., San Mateo, CA, USA }\end{array}$ \\
\hline
\end{tabular}

can reduce the effective dose. Since the radiation received by the thyroid gland contributes a large amount to the effective dose, limiting the beam to the maxilla instead of the whole head produces a lower effective dose.

Tables 2 and 3 provide the most recent published radiation exposures for selected CBCT units using ICRP (2007) recommendations [19-30] and compares them as multiples of digital panoramic examinations (using an average digital panoramic exposure of $14 \mu \mathrm{Sv}$ obtained from the published range of effective dose) and equivalent days of per capita background dose (based on an annual full body background exposure of $3 \mathrm{mSv}$ ). At the time of publication, the CBCT unit with the highest resolution and the smallest field of view (the KODAK 9000 3D) involves patient radiation exposure varying from as little as 0.4 to 2.7 digital panoramic equivalents depending on the part of the mouth studied [30].

4.3. Advantages of CBCT in Endodontics. Perhaps the most important advantage of CBCT in endodontics is that it demonstrates anatomic features in $3 \mathrm{D}$ that intraoral, panoramic, and cephalometric images cannot. CBCT units 
TABle 2: Reported Comparative Radiation Effective Dose $\left(E_{2007}\right)$ from Selected Medium and Full FOV CBCT Systems.

\begin{tabular}{|c|c|c|c|c|c|}
\hline \multirow[b]{3}{*}{ CBCT unit } & \multirow[b]{3}{*}{ Ref. } & \multirow[b]{3}{*}{ Technique } & \multicolumn{3}{|c|}{ Dose $^{\mathrm{a}}$} \\
\hline & & & \multirow{2}{*}{$\begin{array}{c}\text { Absolute } \\
\text { Effective dose }^{\mathrm{a}}(\mu \mathrm{Sv})\end{array}$} & \multicolumn{2}{|c|}{ Comparative } \\
\hline & & & & $\begin{array}{l}\text { Digital panoramic } \\
\text { equivalent }^{\mathrm{b}}\end{array}$ & $\begin{array}{l}\text { No. of days of annual per } \\
\text { capita background }^{c}\end{array}$ \\
\hline \multirow[t]{4}{*}{ CB MercuRay } & {$[16]$} & 100 kVp 12-in/9-in/6-in & $479 / 402 / 369$ & $34 / 29 / 26$ & $58 / 49 / 45$ \\
\hline & {$[16]$} & 120 kVp 12-in/9-in/6-in & $761 / 680 / 603$ & $54 / 49 / 40$ & $93 / 83 / 73$ \\
\hline & {$[17]$} & Implant mode & 511 & 36.5 & 62 \\
\hline & {$[18]$} & $\begin{array}{c}19 \mathrm{~cm}(\mathrm{Max} / \mathrm{Stand}) / 15 \mathrm{~cm} \\
\mathrm{Pan} / 10 \mathrm{~cm} \mathrm{I}\end{array}$ & $1073 / 569 / 560 / 407$ & $77 / 41 / 40 / 20$ & $131 / 69 / 68 / 50$ \\
\hline Galileos & {$[18]$} & Default/Maximum & $70 / 128$ & $5 / 9.1$ & $8.5 / 15.6$ \\
\hline i-Cat Next Gen & {$[18]$} & $\begin{array}{l}\text { (portrait- } 17 \mathrm{~cm} / \text { landscape- } \\
13 \mathrm{~cm} \text { ) }\end{array}$ & $74 / 87$ & $5.3 / 6.2$ & $9 / 10.6$ \\
\hline \multirow[t]{5}{*}{ i-Cat Classic } & {$[19]$} & $22 \mathrm{~cm} / 13 \mathrm{~cm}(40 \mathrm{~s} / 10 \mathrm{~s})$ & $82 / 77 / 48$ & $5.9 / 5.5 / 3.4$ & $10 / 9.4 / 5.8$ \\
\hline & {$[20]$} & $6 \mathrm{~cm} \mathrm{Mn} \mathrm{(HR/LR)}$ & $189 / 96$ & $13.5 / 6.86$ & $23 / 11.7$ \\
\hline & {$[20]$} & $6 \mathrm{~cm} \mathrm{Mx} \mathrm{(HR/LR)}$ & $93 / 59$ & $6.6 / 4.2$ & $11 / 7.2$ \\
\hline & {$[20]$} & $22 \mathrm{~cm} /$ full & $206 / 134$ & $14.7 / 9.6$ & $25 / 16$ \\
\hline & {$[21]$} & $13 \mathrm{~cm}$ & 61.1 & 4.4 & 7.4 \\
\hline Iluma & {$[18]$} & $20 s / 40 s$ & $98 / 498$ & $7 / 35.6$ & $11.9 / 60.6$ \\
\hline Newtom 9000 & {$[21]$} & $23 \mathrm{~cm}$ & 56.2 & 4 & 6.9 \\
\hline \multirow[t]{3}{*}{ Newtom 3G } & {$[22]$} & 12-in (Male/female) & $93 / 95$ & $6.6 / 6.8$ & $11.3 / 11.6$ \\
\hline & {$[18]$} & $19 \mathrm{~cm}$ & 68 & 4.9 & 8.3 \\
\hline & {$[19]$} & $6 / 9 / 12$-in & $57 / 191 / 30$ & $4 / 13.6 / 2.1$ & $6.9 / 23.2 / 3.7$ \\
\hline
\end{tabular}

${ }^{a}$ Using 2007 ICRP calculations.

${ }^{\mathrm{b}}$ Median of published effective dose for digital dental panoramic radiography $=14 \mu \mathrm{Sv}$.

${ }^{\mathrm{c}}$ Annual per capita $=3.0 \mathrm{mSv}(3,000 \mu \mathrm{Sv})$ per annum.

TABle 3: Reported Comparative Radiation Effective Dose $\left(E_{2007}\right)$ for Limited, "Focused" or Small FOV CBCT Systems.

\begin{tabular}{|c|c|c|c|c|c|}
\hline \multirow[b]{3}{*}{ CBCT unit } & \multirow[b]{3}{*}{ Ref. } & \multirow[b]{3}{*}{ Technique } & \multicolumn{3}{|c|}{ Dose $^{\mathrm{a}}$} \\
\hline & & & \multirow{2}{*}{$\frac{\text { Absolute }}{\text { Effective dose }^{\mathrm{a}}(\mu \mathrm{Sv})}$} & \multicolumn{2}{|c|}{ Comparative } \\
\hline & & & & $\begin{array}{c}\text { Digital panoramic } \\
\text { equivalent }^{\mathrm{b}}\end{array}$ & $\begin{array}{l}\text { No. of days of annual per } \\
\text { capita background }^{\mathrm{c}}\end{array}$ \\
\hline Kodak 9000 3D & {$[30]$} & $\begin{array}{c}\text { Mx Post/Mx Ant/Mn } \\
\text { Post/Mn Ant }\end{array}$ & $9.8 / 5.3 / 38.3 / 21.7$ & $.7 / .4 / 2.7 / 1.6$ & $1.2 / .6 / 4.7 / 2.6$ \\
\hline PreXion 3D & {$[18]$} & Standard/High Res & $189 / 388$ & $13.5 / 27.7$ & $23 / 47$ \\
\hline ProMax 3D & {$[18]$} & Small/Large & $488 / 652$ & $35 / 47$ & $59 / 79$ \\
\hline \multirow[t]{5}{*}{ 3D Accuitomo } & {$[23]$} & Ant $(4 \times 4 \mathrm{~cm} / 6 \times 6 \mathrm{~cm})$ & $20 / 43$ & $1.4 / 3.1$ & $2.5 / 5.2$ \\
\hline & {$[24]$} & $\begin{array}{c}\operatorname{Min}(\mathrm{Mn} \mathrm{PM})-\operatorname{Max}(\mathrm{Mn} \\
\text { 3rd Mol })\end{array}$ & $11-77$ & $.8-5.5$ & $2.5-5.2$ \\
\hline & {$[19]$} & $\mathrm{Mx}(\mathrm{Ant} / \mathrm{PM} / \mathrm{Mol})$ & $29 / 44 / 29$ & $2 / 3.2 / 2$ & $3.5 / 5.3 / 3.5$ \\
\hline & & $\mathrm{Mn}(\mathrm{Ant} / \mathrm{PM} / \mathrm{Mol})$ & $13 / 22 / 29$ & $.9 / 1.6 / 2$ & $1.6 / 2.7 / 3.5$ \\
\hline & {$[17]$} & II/FPD Large/FPD Small & $30 / 102 / 50$ & 2.1/7.3/3.6 & $3.6 / 12.4 / 6$ \\
\hline \multirow[t]{2}{*}{ Veraview } & {$[23]$} & $\begin{array}{c}\text { Ant }(4 \times 4 \mathrm{~cm} / 8 \times 4 \mathrm{~cm} / \mathrm{pan} \\
+4 \times 4 \mathrm{~cm})\end{array}$ & $31 / 40 / 30$ & $2.2 / 2.9 / 2.1$ & $3.8 / 4.9 / 3.6$ \\
\hline & {$[25]$} & $4 \times 4 \mathrm{~cm}$ & 2.9 & .2 & .06 \\
\hline
\end{tabular}

${ }^{a}$ Using 2007 ICRP calculations.

${ }^{\mathrm{b}}$ Median of published effective dose for digital dental panoramic radiography $=14 \mu \mathrm{Sv}$.

${ }^{\mathrm{c}}$ Annual per capita $=3.0 \mathrm{mSv}(3,000 \mu \mathrm{Sv})$ per annum. 


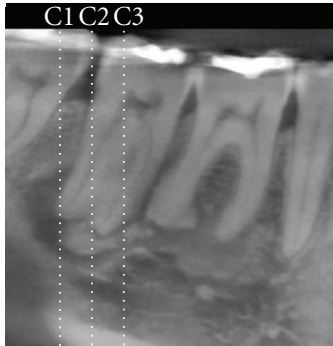

(a)

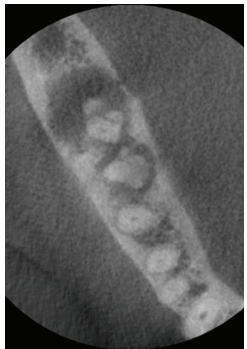

(b)

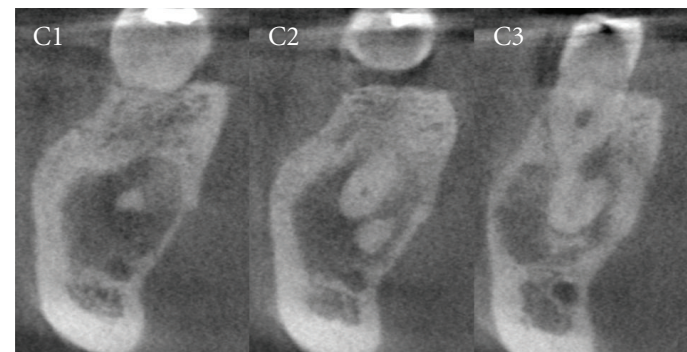

(c)

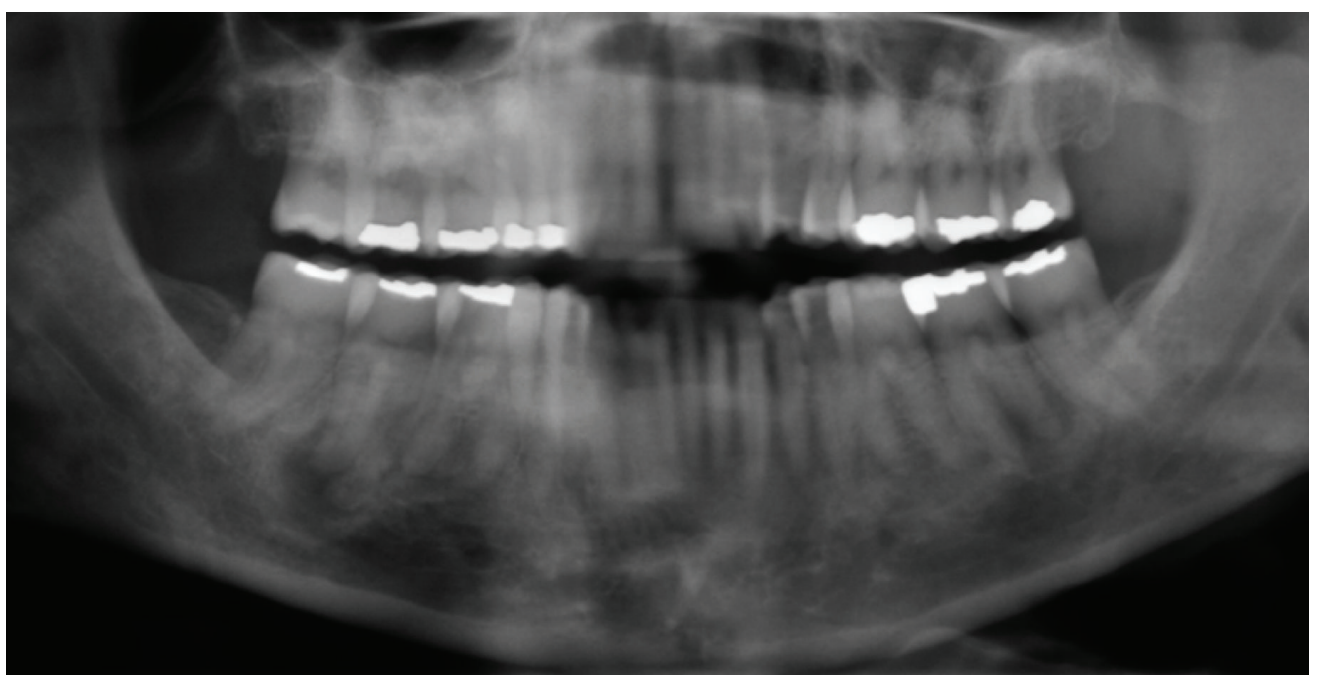

(d)

Figure 2: A 52-year-old Caucasian female was referred for assessment of multiple periapical areas associated with the mandibular right first and second molars. Curved planar (a), axial (b), and correlated multiple cross-sectional (c) images are shown. There are areas of mixed central opacity and peripheral radiolucency associated with the apices of the teeth; however no expansion, tooth resorption, or displacement is evident. Hypercementosis is observed on the distal root of the first molar. On clinical examination, all teeth in this quadrant tested vital. Based on a working diagnosis of florid cemento-osseous dysplasia, an additional digital panoramic radiograph ((d) cropped panoramic image) was performed and revealed similar bony patterns in the left posterior maxilla and mandible. Management of this patient comprised a 6-month recall comparison of focused CBCT images to judge the progression of the lesion.

reconstruct the projection data to provide interrelational images in three orthogonal planes (axial, sagittal, and coronal). In addition because reconstruction of CBCT data is performed natively using a personal computer, data can be reoriented in their true spatial relationships.

Due to the isotropic nature of the constructed volume elements ("voxels") constituting the volumetric dataset, image data can be sectioned nonorthogonally. Most software provides for various nonaxial $2 \mathrm{D}$ images in multiplanar reformation (MPR). Such MPR modes include oblique, curved planar reformation (providing "simulated" distortion free panoramic images) and serial transplanar reformation (providing cross-sections), which can be used to highlight specific anatomic regions for diverse diagnostic tasks (Figure 2). Enhancements including zoom magnification, window/level adjustments, and text or arrow annotation can be applied. Cursor-driven measurement algorithms provide the clinician with an interactive capability for real-time dimensional assessment. On-screen measurements are free from distortion and magnification.

Because acquisition occurs innately as high-resolution three-dimensional volumetric data and can be displayed as interactive images, CBCT technology provides the clinician with an unparalleled visualization of the often complex relationships and boundaries between teeth and their associated pathology and anatomic features within the alveolus and jaws such as the maxillary sinus and mandibular canal and foramen.

4.4. Limitations of $C B C T$ in Endodontics. Despite the provision of the third dimension, the spatial resolution of CBCT images $(0.4 \mathrm{~mm}$ to $0.076 \mathrm{~mm}$ or equivalent to 1.25 to 6.5 line pairs per mm $\left.{ }^{-1}\left[\mathrm{lp} \cdot \mathrm{mm}^{-1}\right]\right)$ is inferior to conventional 
film-based (approx. $20 \mathrm{lp} . \mathrm{mm}^{-1}$ ) or digital (ranging from 8-20 lp. $\mathrm{mm}^{-1}$ ) intraoral radiography [31]. However, the ability of this technology to demonstrate geometrically accurate images in all three dimensions and the elimination of anatomic noise facilitates the assessment of a number of features important in endodontic diagnosis, treatment, and long-term management. The optimal resolution for CBCT images in endodontics is invariably task specifichowever; most aspects of endodontics involve imaging of small structures. Liedke et al. [32] have recommended a minimal voxel resolution of $0.3 \mathrm{~mm}$ for the detection of external root resorption. Ex vivo research performed at our institution [33] has determined the effect of isotropic voxel dimensions on observer detection of the presence or absence of secondary canals in the mesiobuccal root of the maxillary first permanent molar. Observer interrater reliability and detection of mesiobuccal canals increased substantially with increasing resolution with more than 93\% accuracy with a voxel resolution of $0.12 \mathrm{~mm}$ but accuracy barely over $60 \%$ with $0.4 \mathrm{~mm}$ resolution. The diagnosis of other subtle conditions (e.g., initial stages of apical periodontitis) involving the periodontal ligament space, which has an average dimension of $0.2 \mathrm{~mm}$, also demands high resolution.

The CBCT projection geometry results in the whole volume within the FOV being irradiated with every basis image projection. Scattered radiation is produced omnidirectionally and is recorded by pixels on the cone beam CT detector but does not reflect actual attenuation of the object within a specific path of the X-ray beam. Additional recorded $\mathrm{X}$-ray nonlinear attenuation is noise. This can be eliminated somewhat by algorithms such as wavelet transformation of filtered back-projection data; however, because of the use of an area detector, some of this nonlinear attenuation is recorded and contributes to image degradation when not adequately attended to by noise reduction algorithms. Remaining noise contributes to the graininess of the image which can be more pronounced in images in systems using a large FOV, especially where low signal due to restricted radiation exposure is the case.

Maxillofacial CBCT images presently lack the ability to record subtle changes in attenuation across a wide range of tissue radiodensities. In endodontics, contrast resolution might well be of importance in distinguishing the nature of periapical or sinus soft tissue contents. Three factors, inherent in the CBCT acquisition process, presently limit contrast resolution: (1) scattered radiation contributing to the potential for increased noise, (2) CBCT systems pronounced "heel effect" due to the divergence of the Xray beam over the area detector producing nonuniformity of the incident X-ray beam, and (3) detector imperfections affecting linearity in response to $\mathrm{x}$-radiation. These factors, and a desire to restrict dose, contribute to restricting the application of current maxillofacial CBCT imaging to the assessment of osseous structures. Work continues to develop systems capable of a wide contrast range supporting both hard tissue and soft tissue applications while still limiting dose.
CBCT images, like those from other diagnostic modalities, are susceptible to artifacts that affect image fidelity. Artifacts can be attributed to four sources [34]: (1) the patient; (2) the scanner; (3) artifacts specific to the CBCT system used including partial volume averaging, undersampling, and the cone beam effect; and (4) X-ray beam artifacts arising from the inherent polychromatic nature of the projection Xray beam that results in what is known as beam hardening (i.e., mean energy increases because lower energy photons are absorbed in preference to higher-energy photons). Beam hardening results in two types of artifact: (1) distortion of metallic structures due to differential absorption, known as a cupping artifact; and (2) streaks and dark bands that can appear between two dense objects. The presence of dental restorations, including apically positioned retrograde restorations, in the FOV can lead to severe streaking artifacts. As the CBCT X-ray beam is heterochromatic and has lower mean $\mathrm{kVp}$ energy compared to conventional CT, such artifact can be pronounced in CBCT images. In clinical endodontic practice, CBCT scanners with a limited field of view might provide clearer images as they can avoid scanning structures outside the region of interest susceptible to beam hardening (e.g., metallic restorations, dental implants).

\section{CBCT Applications in Endodontics}

A PUBMED search performed in May 2009 (search terms: cone beam, СВCT, endodontics, root canal, periapical) resulted in less than 30 comparative retrospective or ex vivo studies published quantifying specific clinical efficacies of CBCT imaging in endodontics. Similarly a recent review performed by the SEDENTEXCT project indicated that while several nonsystematic reviews in the literature provide a favorable perspective of the role of CBCT imaging in endodontics, only a few studies have been published that satisfy the criteria for formal systematic review [35].

While there are presently no definitive patient selection criteria for the use of CBCT in endodontics, the use of $\mathrm{CBCT}$ in endodontic diagnosis should not be avoided or ignored. One of the authors (Martin D. Levin) is a Board Certified Endodontist with a full time private practice with limited field CBCT. CBCT has been used to assist diagnosis and facilitate treatment in more than half of all patients referred to his practice for assessment and treatment of complex endodontic conditions (Figures 3 and 4).

Depending on the equipment used, СВСТ exposure may subject a patient to only slightly higher radiation doses than conventional 2D imaging - or considerably more, so it is important that practitioners follow professional judgment in minimizing the radiation dose to the patient to that deemed essential for optimal diagnosis and treatment guidance. There should be justification of the exposure to the patient such that the total potential diagnostic benefits are greater than the uncertain detriment radiation exposure might cause. Published research, while admittedly sparse, indicates that СВCT has several applications in selected endodontic cases (Figures 5 and 6). The absence of high 


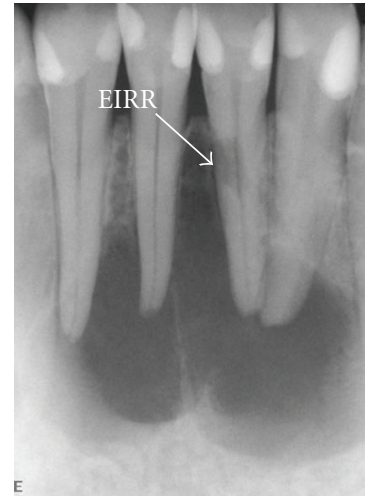

(a)

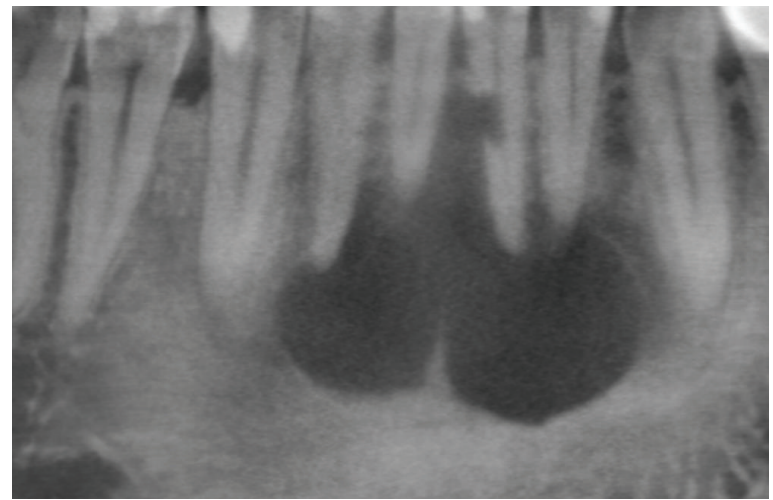

(b)

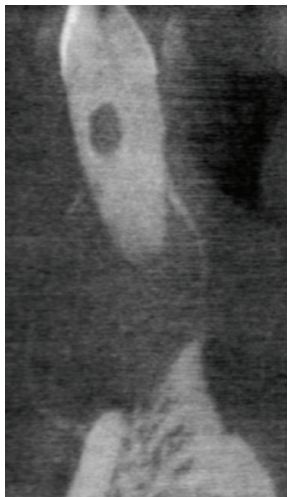

(c)

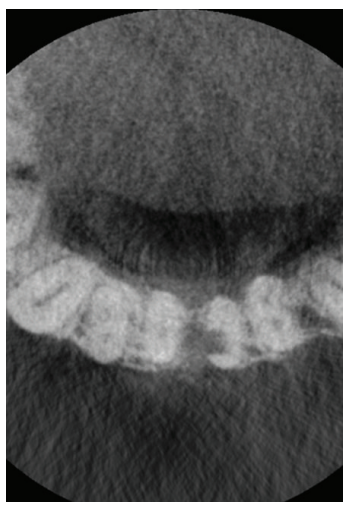

(d)

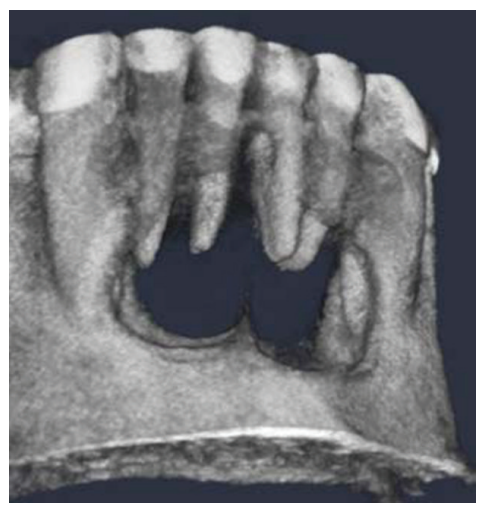

(e)

Figure 3: After suffering a traumatic blow from a soccer ball six years earlier, a 28-year-old male presented with a soft, convex-shaped indurated buccal and lingual swelling in the mandibular symphyseal region. A periapical image (a) showed a large, multilocular lesion. External inflammatory root resorption (EIRR) was noted on the mandibular left lateral incisor. All four mandibular anterior teeth tested nonvital. CBCT images ((b) curved planar, (c) cross-sectional, (d) axial, (e) 3D reconstruction) showed that the resorptive lesion was extended from the root canal space to the periodontal membrane, necessitating repair or extraction; no exploratory procedure was necessary to determine the extent of the defect.

prospective randomized clinical trials underlines the need for further research on the treatment outcomes related to CBCT applications in endodontic practice. At this time CBCT should not be considered a replacement for standard digital radiographic applications. Rather, CBCT is a complementary modality for specific applications [35].

\subsection{Preoperative Assessment}

5.1.1. Tooth Morphology. The success of endodontic treatment depends on the identification of all root canals so that they can be accessed, cleaned, shaped, and obturated [36]. The prevalence of a second mesiobuccal canal (MB2) in maxillary first molars has been reported to vary from $69 \%$ to $93 \%$ depending on the study method employed. This variability occurs in the buccolingual plane where superimposition of anatomic structures impedes detection of small structural density changes $[37,38]$. Conventional radiographic techniques, at best, can only detect up to $55 \%$ of these configurations (Figure 7) [39]. Ramamurthy et al. [40] found that raters evaluating different two- dimensional film modalities were rarely able to detect more than a 50\% presence of MB2 canals. They found differences in detection rates with complementary metal oxide semiconductors (CMOSs), analog film, and photostimulable phosphor plates (PSP) detecting 55\%, 44\%, and 39\% of MB2 canals, respectively. Matherne et al. [41] compared the ability of three board-certified endodontists to detect the number of root canals on intraoral digital (both charged-couple device and photostimulable phosphor) plate images with CBCT in 72 extracted teeth ( 3 equal groups of maxillary molars, mandibular premolars, and mandibular incisors). They found that on average the observers failed to detect at least one root canal in $40 \%$ of teeth using intraoral radiographs. CBCT evaluations identified an average of 3.58 root canals (RCS) per maxillary molar, 1.21 per mandibular premolar, and 1.5 per mandibular incisor. Evaluation of CCD images demonstrated an average number of 1.0 RCS per mandibular incisor, 1.0 per mandibular first premolar, and 3.1 per maxillary molar. Evaluation of PSP images demonstrated an average number of 1.3 RCS per mandibular incisor, 1.1 per mandibular first premolar, and 3.0 per maxillary molar. 


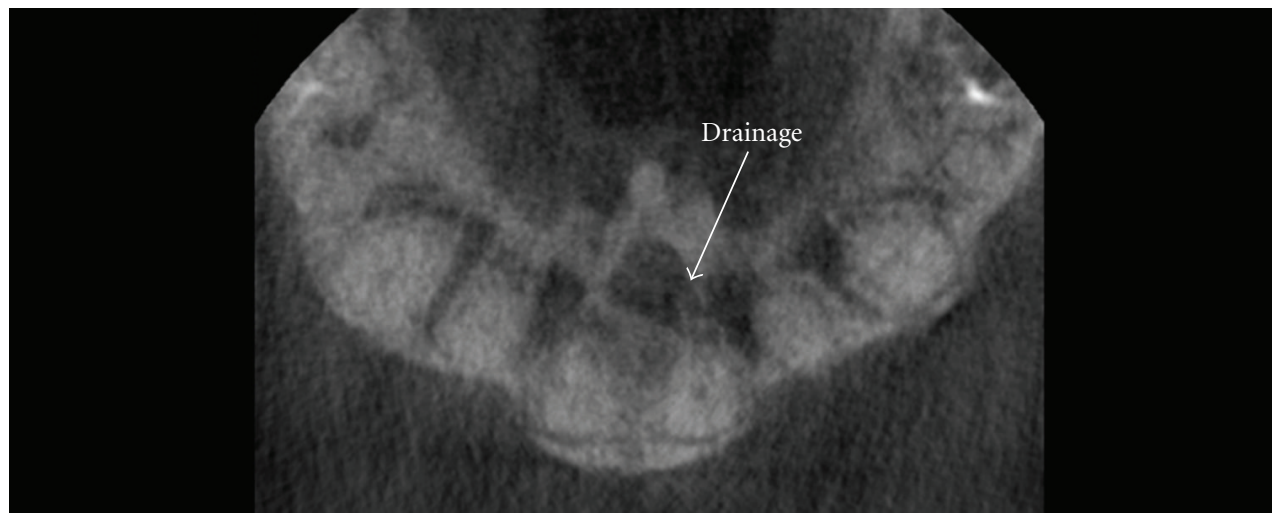

(b)

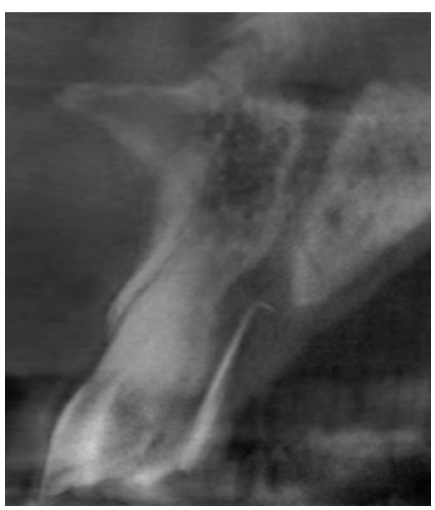

(a)

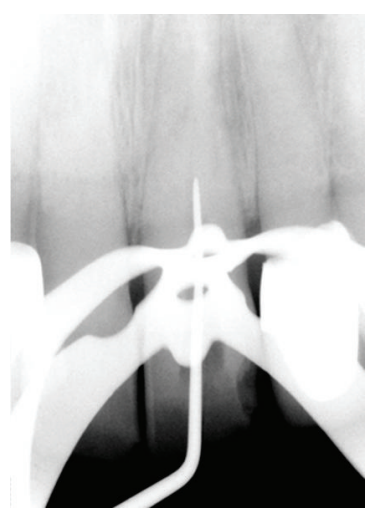

(c)

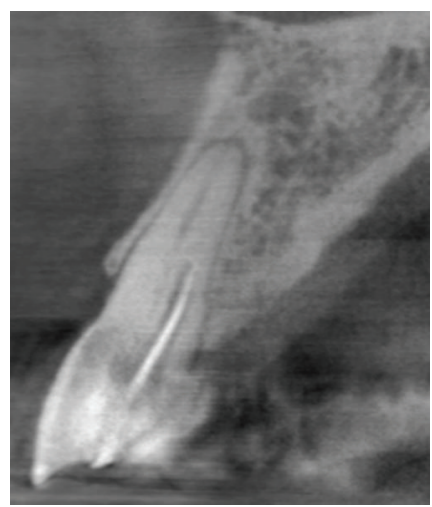

(d)

FIGURE 4: A 79-year-old male was referred for endodontic treatment of the maxillary left central incisor after a palatal sinus tract was noted. CBCT imaging was initially performed with a gutta percha cone marker inserted into the sinus tract to determine the source of the infection. Sagittal images (a) demonstrated that the lesion terminated at the periapex of the maxillary left central incisor after coursing through the incisive canal whereas drainage was visible on the axial image (b). Perioperatively, only the mesiodistal direction could be determined on conventional intraoral periapical radiography (c) and treatment suspended when the explorer reached $17 \mathrm{~mm}$ because of the danger of perforation in the facial or palatal direction. Subsequent cross-sectional perioperative CBCT imaging (d) with an intracanal gutta percha marker indicated that the initial access preparation was directed palatally. Correction of the access facially resulted in gaining access to the apical terminus; treatment was completed without complication.

Baratto Filho et al. [42] investigated the internal morphology of extracted maxillary first molars by comparing detection rates obtained using an operating microscope and CBCT to ex vivo sections. They reported an ex vivo prevalence of a fourth canal in $67.14 \%$ of teeth and additional root canals in $92.85 \%$ of mesiobuccal roots. Clinical assessment provided slightly lower overall (53.26\%) but higher $(95.63 \%)$ MB2 detection rates whereas CBCT results showed the lowest overall $(37.05 \%)$ detection rate. They indicated that CBCT provided a good method for the initial evaluation of maxillary first molar internal morphology but that the use of operating microscopes was optimal. Unpublished ex vivo research performed at our institution [33] investigated the effect of increasing voxel resolution on the detection rate of multiple observers of the MB2 on 24 maxillary first molars by CBCT. Compared to the overall prevalence of MB2 (92\% prevalence), CBCT detection rates increased from $60 \%$ to $93.3 \%$ with increasing resolution suggesting that if CBCT is to be used, then resolutions in the order of $0.12 \mathrm{~mm}$ or less are optimal.

CBCT imaging has also been reported to characterize the high prevalence of the distolingual canal in Taiwanese individuals [43], highlight anomalies in the root canal system of mandibular premolars [44], and assist in the determination of root curvature [45].

5.1.2. Dental Periapical Pathosis. The most common pathologic conditions that involve teeth are the inflammatory lesions of the pulp and periapical areas (Figures 8, 9, 10, and 11). Lofthag-Hansen et al. [46] compared the accuracy of 3 observers using high-resolution limited FOV CBCT to intraoral radiographic paralleling technique using two images, one with a horizontal tube shift difference of about $10^{\circ}$ for the diagnosis of periapical pathology on 46 teeth. While CBCT and intraoral radiographs identified 53 roots with lesions, CBCT identified an additional 33 roots with 


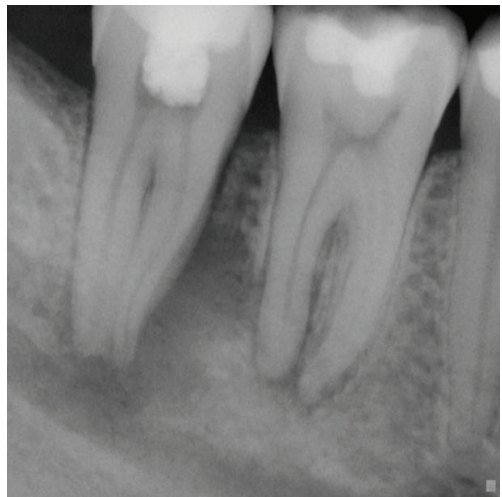

(a)

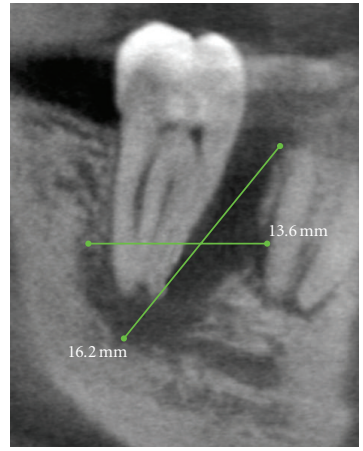

(b)

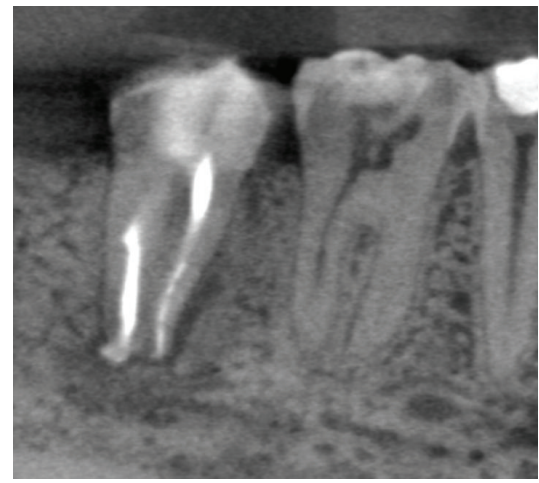

(e)

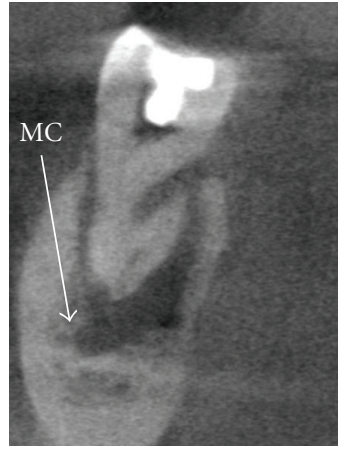

(c)

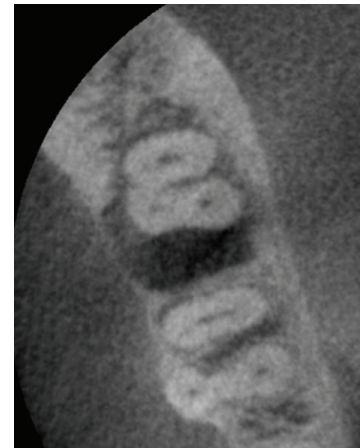

(d)

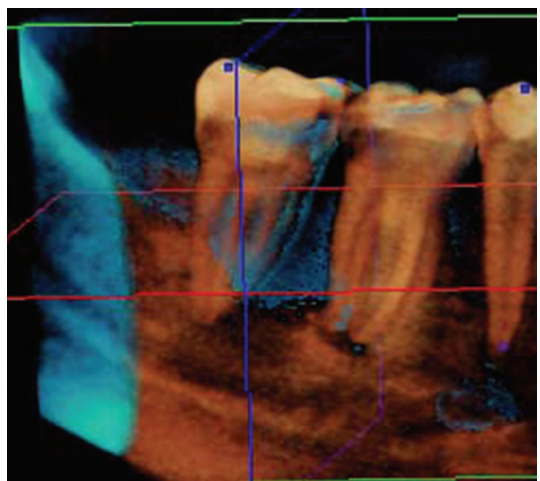

(f)

FIGURE 5: Treatment of large destructive lesions associated with pulpal pathosis benefit from 3D imaging providing better visualization of the spatial relationships of the tooth to anatomic landmarks and canal morphology. This patient presented with mild dysthesia of the right mandibular dentition. Conventional periapical imaging (a) demonstrated a large apical and mesial ill-defined rarefaction associated with the right mandibular second molar in close proximity to the inferior alveolar nerve. CBCT images ((b) sagittal, (c) cross-sectional, (d) axial) demonstrate the proximity of the lesion to the mandibular canal (MC). Therefore during treatment great care was taken to prevent obturation material extrusion past the apical terminus and possible traumatization of the IAN. Additional parasagittal CBCT images document the progression of healing at 6 months (e). In addition digital subtraction composite 3D imaging at 6 months (f) provides three-dimensional visualization of healing. (Data acquired at $0.076 \mathrm{~mm}$ resolution on an KODAK Dental Imaging 9000 DS (Dental Imaging/Practiceworks Atlanta, GA, USA) and 3D subtraction composite reformatted using InVivo Dental (Anatomage, San Jose, CA)).

lesions (62\%). Observers agreed that additional clinically relevant material was provided by CBCT imaging in 32 of the $46(69.5 \%)$ teeth imaged. Stavropoulos and Wenzel [47] compared CBCT (NewTom 3G) to digital- and filmbased intraoral periapical radiography for the detection of periapical bone defects on 10 frozen pig mandibles by four calibrated examiners. They reported that CBCT provides greater diagnostic accuracy (61\%) compared with digital (39\%) and (44\%) conventional radiographs. Özen et al. [48] performed a similar study comparing the detection of chemically induced periapical lesions by three observers using digital- and film-based conventional radiography to two CBCT systems (Iluma, Imtec Imaging, Ardmore, OK and iCAT, Imaging Sciences International, Hatfield, PA). They found that CBCT systems provided similar intra- and interobserver agreement substantially higher than either conventional radiography. They indicated that while detection rates for CBCT were higher, they did not advocate the replacement of intraoral radiography for detecting periapical lesions in routine clinical practice due to financial and dose considerations.

Estrela et al. [49] compared the accuracy of CBCT, panoramic and periapical radiographs from a consecutive sample of 888 imaging exams of patients with endodontic infection (1,508 teeth) in the detection of apical periodontitis (AP). While a gold standard was not available, they found the detected prevalence of AP to be significantly higher with CBCT (Figure 12). Estrela and colleagues proposed a periapical index based on cone beam-computed tomography (CBCTPAI) for identification of AP [50]. The CBCT PAI is a 6-point (0-5) scoring system calculated from determining the largest lesional measurement in either the buccopalatal, mesio-distal, or diagonal dimension and taking into account expansion and destruction of cortical bone. Using their criteria, 3 observers applied it to 1,014 images (periapical radiographs and high resolution CBCT images) originally taken from 596 patients. They found that CBCT imaging detected $54.2 \%$ more AP lesions than intraoral radiography 


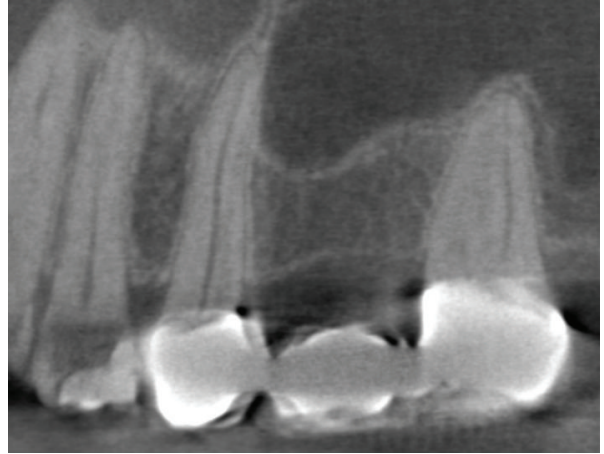

(a)

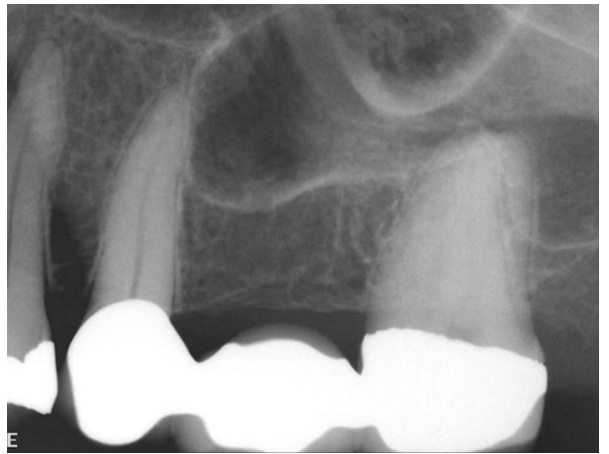

(b)

Figure 6: A female patient presented with a twenty-year history of mostly continuous, unilateral, poorly localized severe aching of the maxillary left quadrant. The pain was not associated with sensory loss or other physical signs and pulp tests, and conventional imaging studies were within normal limits. Clinically there was no cessation of pain after administration of local anesthetic. This neuropathic pain syndrome, initially termed atypical facial pain, is more recently known as persistent idiopathic facial pain (PIFP). PIFP refers to pain along the territory of the trigeminal nerve that does not fit the classic presentation of other cranial neuralgias. Diagnostically challenging, PIFP is frequently misdiagnosed and is often attributed by patients to dental procedures, facial trauma, and rarely, by some clinicians, as NeuralgiaInducing Cavitational Osteonecrosis (NICO). Dynamic visualization of sequential curved planar parasagittal CBCT-reformatted images at $0.076 \mathrm{~mm}$ thickness (a) confirmed the absence of obvious pathosis of odontogenic origin as diagnosed from the original intraoral periapical of the region (b). Note the radiolucent area within the coronal portion of the first molar under the radiopaque disto-occlusal restorative material; this represents a streak artifact due to "photostarvation" in the horizontal plane due to the attenuation of adjacent amalgam and radiopaque material and subsequent reduction in available data for image reconstruction. A negative CBCT imaging finding is often very reassuring for these unfortunate patients who often question a nonodontogenic diagnosis. Psychiatric symptoms of depression and anxiety are prevalent in this population and compound the diagnostic conundrum.

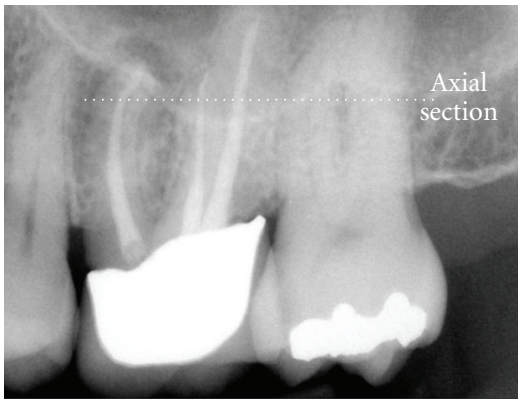

(a)

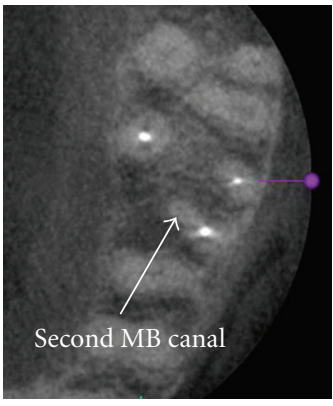

(b)

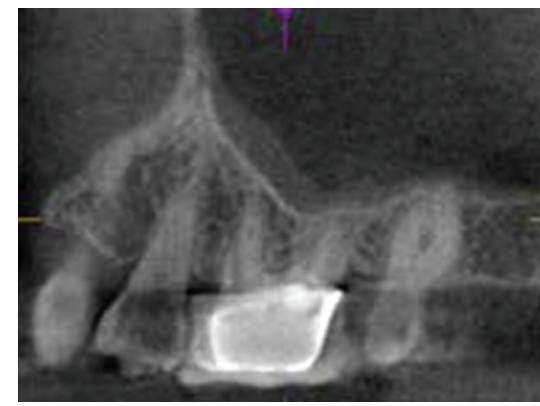

(c)

Figure 7: Maxillary first and second molars often present treatment challenges because of the frequent presence of mesioaccessory (mb2) canals. On initial periapical radiographic examination of this previously treated maxillary left first molar, no mb2 canal was detected; however a periapical lesion is seen (a). Note the overlap of the interproximal contacts between the molars indicating a geometric distortion in the horizontal plane. CBCT imaging ((b) $0.076 \mathrm{~mm}$ axial and (c) 0.076 parasagittal) clearly demonstrates an additional canal that was not previously treated.

alone. Similar results are reported by Low et al. [51] who compared the preoperative consensus assessment of the apical condition of 37 premolars and 37 molars in the maxilla (156 total roots) using periapical radiography and CBCT referred for possible apical surgery and found the later method to demonstrate significantly more lesions (34\%) than conventional radiography. CBCT showed significantly more findings including expansion of lesions into the maxillary sinus, sinus membrane thickening, and missed canals. Using an ex vivo model consisting of $2 \mathrm{~mm}$ diameter defects placed in the cancellous bone at the apices of 10 first molar teeth on six partially dentate intact human dry mandibles, Patel et al. [52] reported a detection rate of $24.8 \%$ and $100 \%$ for intraoral radiography and CBCT imaging respectively.

The generally higher detection rates afforded by CBCT are similar to those reported for conventional CT [53]. This may be of clinical importance in patients who present with pain or who have poorly localized symptoms associated with an untreated or previously root treated tooth with no evidence of pathology identified by conventional imaging [54-56]. 


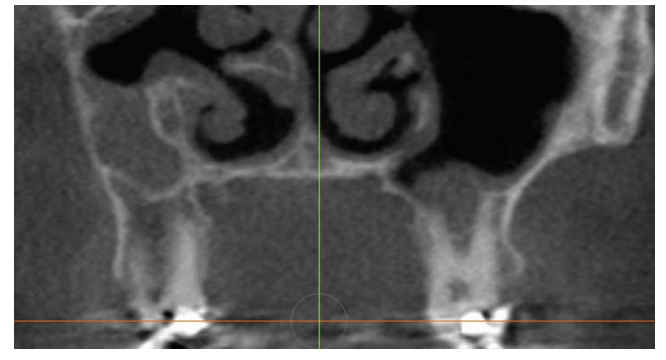

(a)

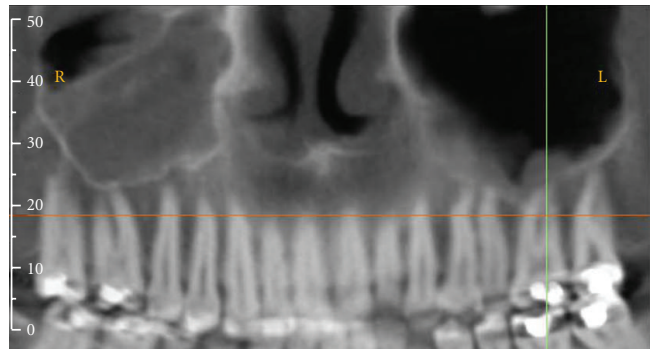

(b)

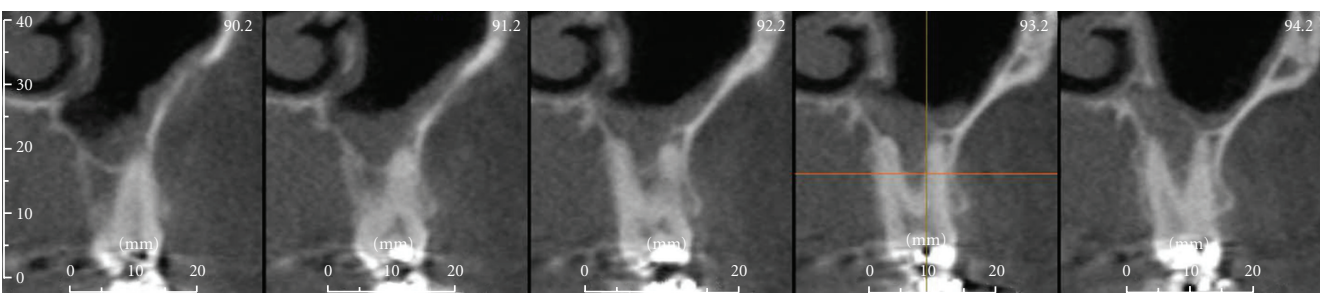

(c)

FIGURE 8: On conventional intraoral periapical radiography periapical mucositis (PM) presents as a relatively radiopaque, soft-tissue, dome-shaped lesion localized to the apex of a maxillary posterior tooth and projecting into the floor of the maxillary sinus. Most are indistinguishable from mucosal lesions of intrinsic sinus origin such as antral mucosal pseudocysts (see Figure 9). While clinically asymptomatic, they are usually associated with necrotic or failing root canal-filled teeth. PM is a localized mucosal thickening of the sinus membrane, secondary to a breach of periradicular inflammation, and will resolve after successful endodontic treatment. This patient gave a history of persistent left side pain over the maxillary molar region of 4-month duration. Treatment for sinusitis did not relieve the symptoms. Panoramic and intraoral dental radiology did not reveal a cause. Coronal CBCT imaging (a) demonstrates acute sinusitis bilaterally with $50 \%$ to $70 \%$ opacification and previous uncinectomy and antrostomy (as evidenced by the loss of the superior medial wall of the right sinus) of the right sinus, whereas the left sinus shows thickened mucosal lining with a dome-shaped soft tissue lesion overlying the roots of the restored left maxillary first molar tooth. $5 \mathrm{~mm}$ reformatted panoramic (b) and $1 \mathrm{~mm}$ cross-sectional (c) reconstructions of the maxillary left first molar show periapical lesional penetration and communication with the floor of the sinus in this region. Data acquired on an iCAT, Imaging Sciences International, Hatfield, PA USA at $0.3 \mathrm{~mm}$ resolution and reformatted using InVivo Dental, Anatomage, San Jose, CA.

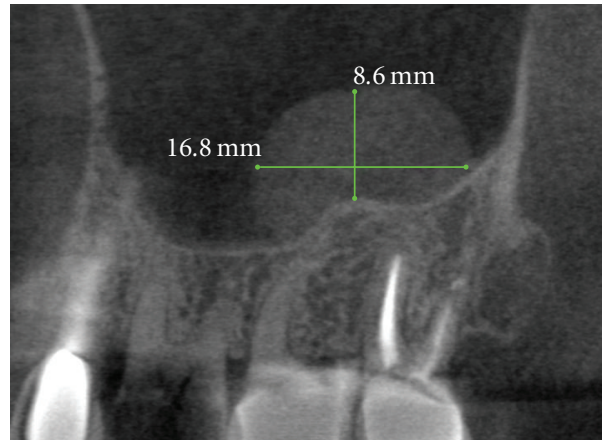

(a)

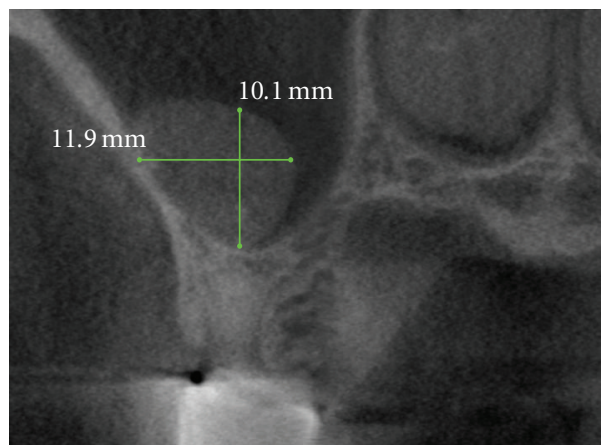

(b)

FIGURE 9: Antral mucosal pseudocysts, also called mucus retention cysts, are a relatively common localized dome-shaped antral mucosal swelling, often of allergic origin and while they can occur anywhere in the sinus present diagnostic challenges when associated with the floor of the maxillary sinus. CBCT imaging ((a) sagittal, (b) cross-sectional) can be useful in differentiating these lesions from periapical mucositis in that the former is usually not associated with disruption of the floor of the sinus and expansion superiorly from the apex of roots of adjacent teeth. 


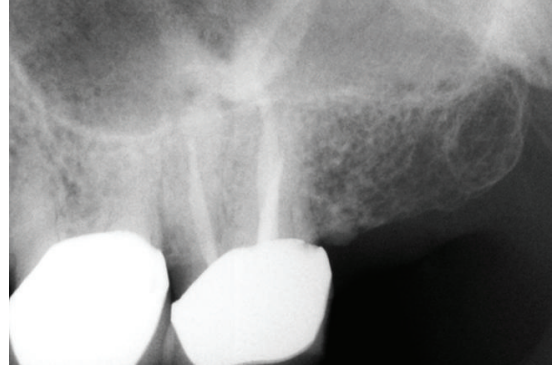

(a)

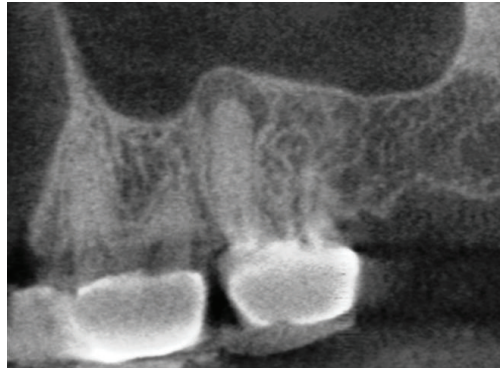

(b)

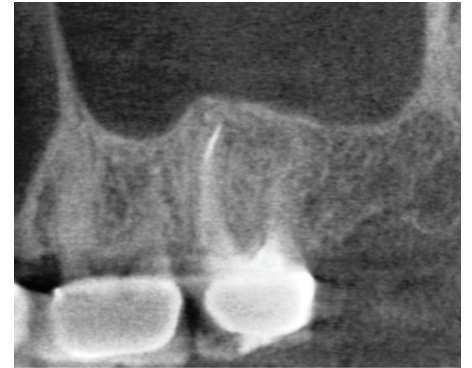

(c)

FIGURE 10: A periapical radiograph of the maxillary left first molar (a) shows an area of low density surrounding the mesial root with incomplete endodontic treatment. A contemporaneous CBCT parasagittal image (b) shows a chronic periradicular osteoperiostitis, or "halo lesion," where the apical periodontitis has caused displacement of the periosteum but did not penetrate the antral floor. Three months after retreatment, CBCT imaging (c) demonstrates complete apical resolution.

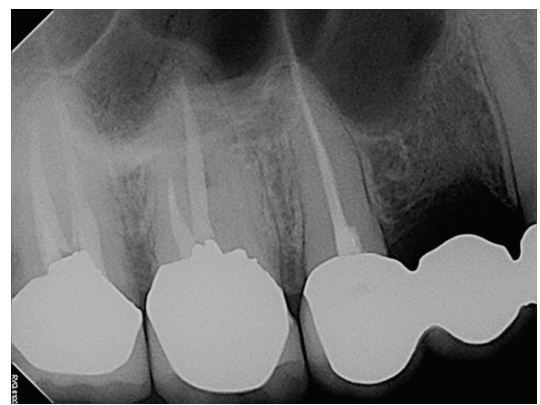

(a)

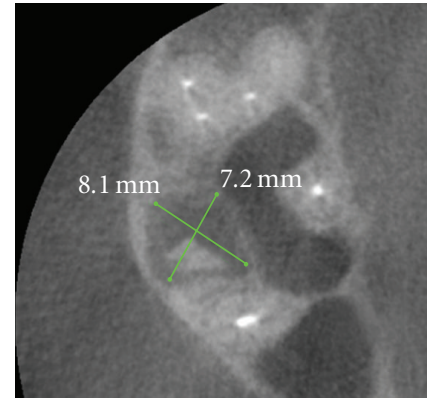

(b)

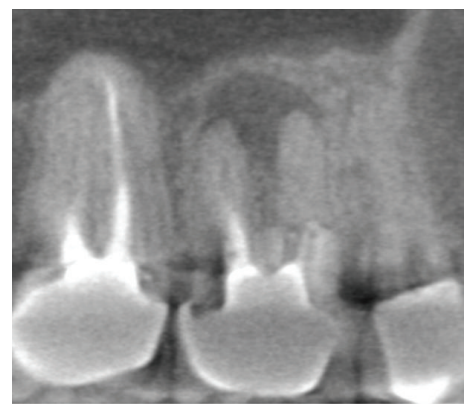

(c)

FIGURE 11: This patient was referred for discomfort and swelling in the maxillary right quadrant. While an initial periapical radiograph (a) clearly demonstrated an untreated mesial root in the maxillary first molar, periradicular periodontitis was undetectable. CBCT images ((a) axial, (b) sagittal) clearly identify a large apical radiolucent lesion associated with the mesial root extending to the distobuccal root. The tooth was retreated and the symptoms subsided.

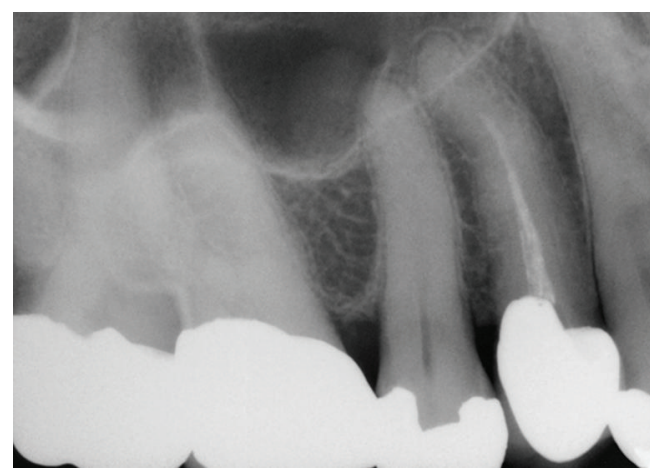

(a)

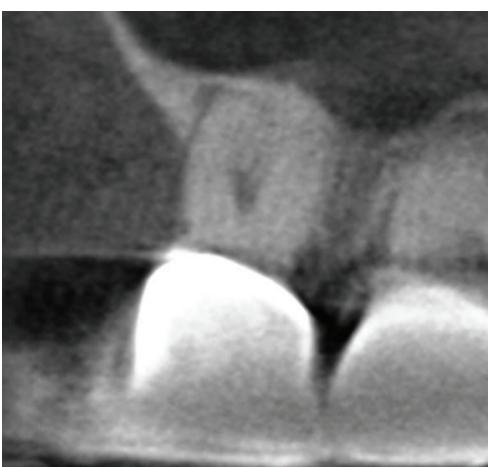

(b)

FIGURE 12: Difficulty in visualizing furcal and apical lesions with periapical radiography due to lack of coverage, anatomic superimposition, and geometric distortion is well established. The periapical radiograph (a) of the maxillary right second molar in an asymptomatic patient is unremarkable; however there is lack of coverage of the second molar posteriorly and marked superimposition of the distal root of the first molar over the mesial root of the second molar. The corresponding cropped sagittal CBCT image (b) of the second molar demonstrates a furcal radiolucency and associated periradicular periodontitis. Subsequent clinical investigation found this tooth to be nonvital. 


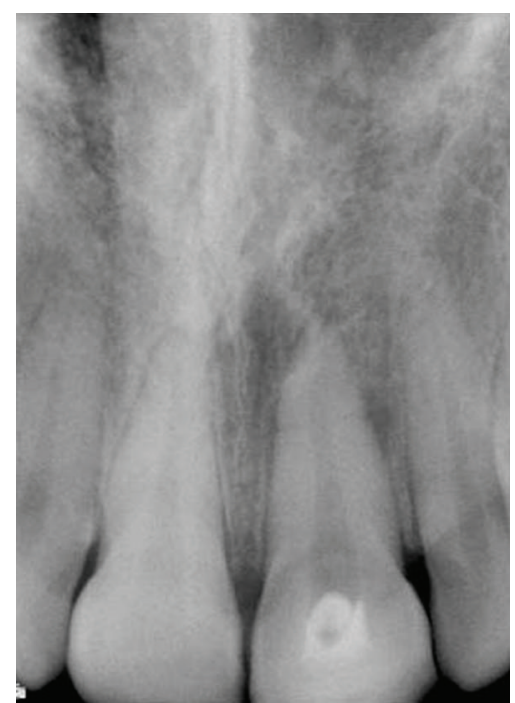

(a)

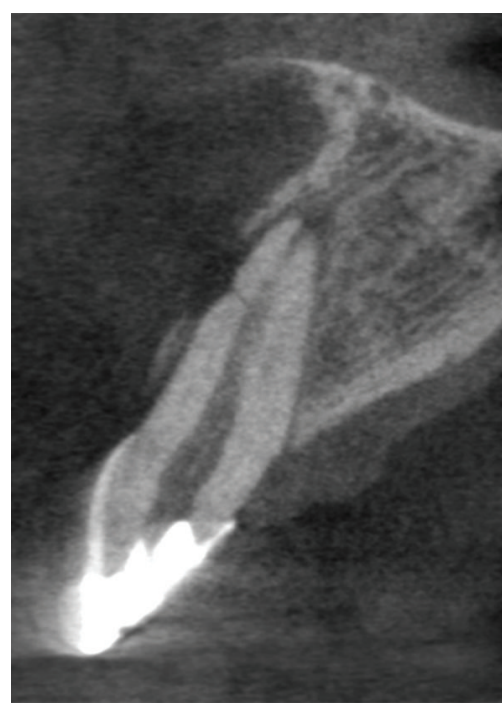

(b)

FIGURE 13: Traumatic injuries to the anterior dentition may result in a horizontal root fracture. Visualizing these fractures with periapical radiographs can be difficult as the beam must be in parallel alignment to the axis of the fracture. Conventional periapical image (a) shows horizontal radiolucent line separating the apical 1/3rd of the root. Note the loss of lamina dura and lateral radiolucency on the distal root surface adjacent to the horizontal radiolucency. Cross-sectional high-resolution $(0.076 \mathrm{~mm})$ image showing "V" shaped fracture and minimal displacement of the root segments. Note the loss of buccal cortical plate, widening of the buccal periodontal ligament space and periapical rarefaction.

5.1.3. Root Fracture. While root fractures are less common than fractures of the crown and occur in only $7 \%$ or fewer of dental injuries $[57,58]$, they are difficult to diagnose accurately using conventional radiography. Numerous authors have illustrated the usefulness and importance of CBCT in the diagnosis and management in specific aspects of dentoalveolar trauma, especially root fractures (Figure 13) [5962], luxation and/or displacement, and alveolar fracture [60]. CBCT has found particular application for the diagnosis of root fractures. Hassan et al. [63] compared the accuracy of 4 observers in detecting ex vivo vertical root fractures (VRFs) on CBCT and periapical images and assessed the influence of root canal filling on fracture visibility. They found an overall higher accuracy for CBCT (0.86) scans than periapical radiographs (0.66) for detecting VRF which was slightly reduced by the presence of opaque obturation material. Similar results were reported by Kamburoğlu et al. [64] who compared the diagnostic accuracy of 3 oral and maxillofacial radiologists in detecting simulated horizontal root fractures on conventional radiographic (analog film, PSP and CCDbased digital) images and CBCT of 36 teeth. They found that the sensitivity of CBCT (0.92) was significantly greater than analog film (0.74), PSP (0.71), and CCD (0.68) images. Most recently Bernardes et al. [65] retrospectively compared conventional periapical radiographs and CBCT images for 20 patients with suspected root fractures. They found that CBCT was able to detect fractures in 18 (90\%) of patients whereas conventional periapicals could only detect fractures 6 to 8 of the cases (30\% to $40 \%$ ) and indicated that CBCT was an excellent supplement to conventional radiography in the diagnosis of root fractures.

5.1.4. Root Resorption. The use of serial cross-sectional CT in diagnosing the size and location of external root resorption (ERR) has been well described (Figures 14 and 15) [6668]. Similarly, several authors have presented selected cases illustrating the utility of CBCT in the detection of small lesions, localizing and differentiation the resorption from other conditions, classification of the lesion, in determining prognosis, and directing treatment (Figures 14 and 15) $[54,69-73]$. The accuracy of CBCT in the detection of surface defects, while higher than conventional imaging modalities, is not perfect [73] and appears to increase with increasing voxel resolution of the volumetric dataset [30]. CBCT has also been shown to have particular application in the assessment of the postorthodontic apical root resorption [74] and, in particular, of the roots of lateral maxillary incisors by impacted maxillary canines [75-77].

Internal root resorption (IRR) within the root canal itself is rare, usually asymptomatic, slowly progressing, and presents as a serendipitous finding on intraoral radiographic examination. The inflammatory etiology of the resorptive process is not fully understood, although IRR has been associated with a history of trauma, persistent chronic pulpitis, and as well as orthodontic treatment. It is very common that internal and external inflammatory root resorption are confused and misdiagnosed. Still, accurate assessment is essential as these conditions represent totally different 


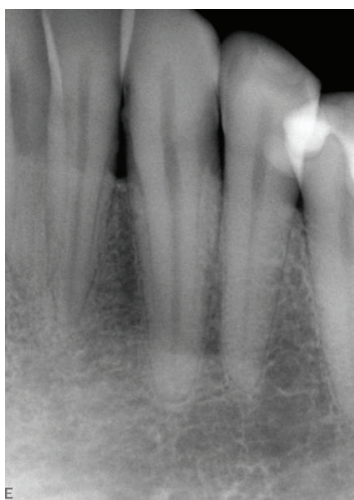

(a)

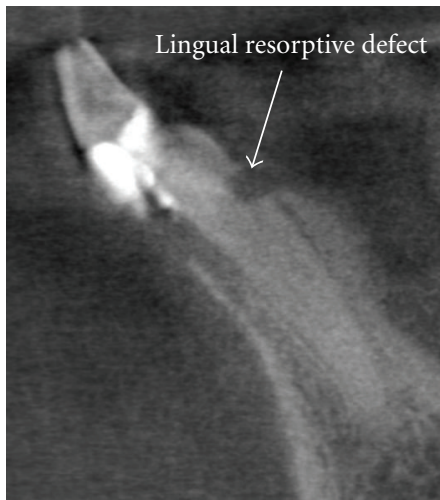

(b)

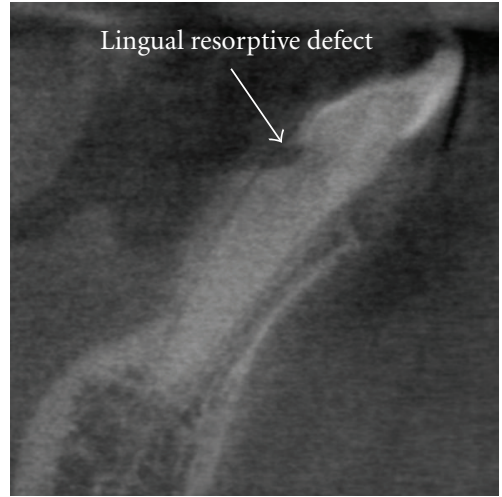

(c)

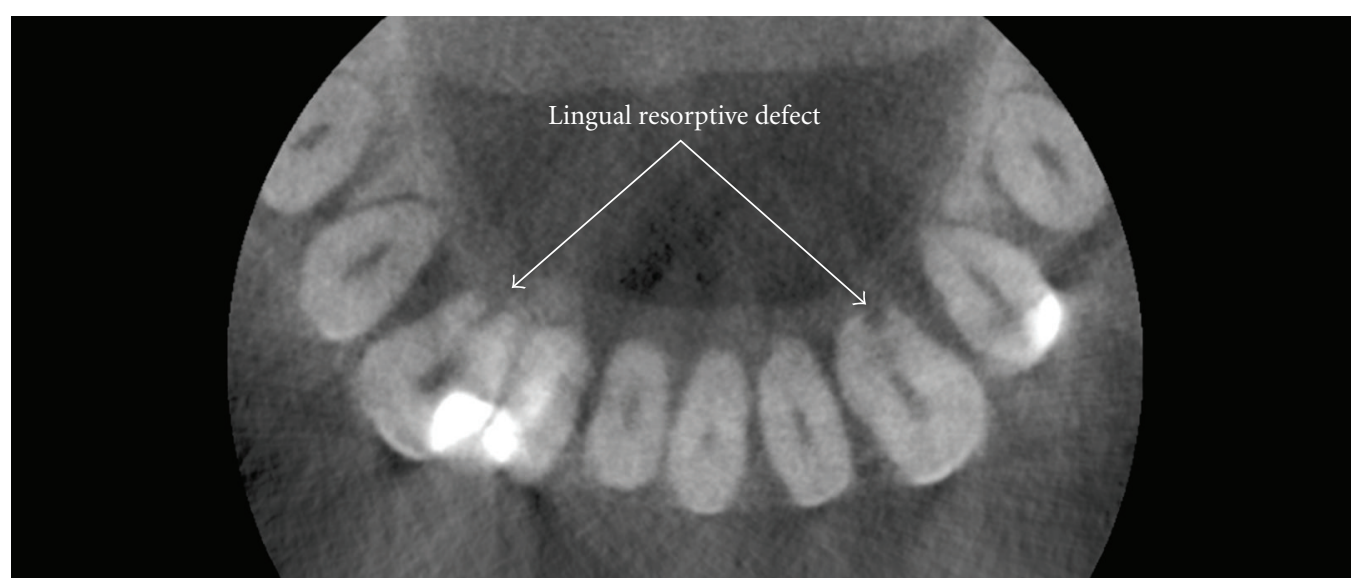

(d)

FIgURE 14: This patient was referred for endodontic revision of the mandibular right lateral incisor. Initial periapical radiographic examination of the mandibular anterior teeth including the left anterior (a) was unremarkable. Note the appearance of a large radiolucency at the on the distal surface of the left canine due to nonperpendicular X-ray beam projection of the distal curvature of the cervical margin. CBCT images ((b) right cross-sectional, (c) left cross-sectional, (d) axial) demonstrated an occult finding of early ERR on the mandibular left and right mandibular cuspids. Early detection and classification of the lesion improve the prognosis and assist in early direct treatment consisting of surgical exposure and removal of granulation tissue from the resorbing lacunae and sealing.

pathological processes, with different etiological factors and treatment protocols. Diagnosis using conventional radiography is difficult; however, unlike external resorption, which presents with irregular radiolucency and intact root canal, internal resorption has clearly defined borders with no canal radiographically visible in the defect (Figure 16) [78]. CBCT has been used successfully to confirm the presence of IRR and differentiate it from ERR [71].

5.2. Postoperative Assessment. Monitoring the healing of apical lesions is an important aspect of postoperative assessment in endodontics. Pinsky et al. [79] investigated the accuracy of CBCT (iCAT with $0.2 \mathrm{~mm}$ voxel resolution) in the detection of the simulated osseous defects of varying diameters and depths in an acrylic block and on the buccal cortex of a human mandible. They found mean accuracy for the acrylic block to be within the tolerance of the nominal resolution of the CBCT unit $(-0.01 \mathrm{~mm} \pm 0.02$ (SE) mean width difference and $-0.03 \mathrm{~mm} \pm 0.01$ (SE) mean height difference). For the human mandible, they found differences to be slightly higher (mean width accuracy, $-0.07 \mathrm{~mm}( \pm 0.02 \mathrm{SE})$; mean height accuracy, $-0.27 \mathrm{~mm}( \pm 0.02 \mathrm{SE})$ ). In addition they segmented the defect and applied and automated algorithm to calculate volume. They found that automated volume accuracy error was significantly higher $\left(-6.9 \mathrm{~mm}^{3}( \pm 4\right.$ $\mathrm{SE})$ ) than manually derived measurements $\left(-2.3 \mathrm{~mm}^{3}\right.$ $( \pm 2.6 \mathrm{SE}))$.

As adequacy of root canal obturation is an important determinant of endodontic success, it might be considered that CBCT is used in the initial and subsequent monitoring of the integrity of root canal fillings. Soğur et al. [80] compared the subjective quality of 3 radiologists and 3 endodontists using limited field CBCT, storage phosphor plate (SPP), and F-speed analog film images for the evaluation of length and homogeneity of root fillings on 17 extracted permanent mandibular incisor teeth. They found that SPP and F-speed film images were perceived as superior to the corresponding CBCT images and they reported that 


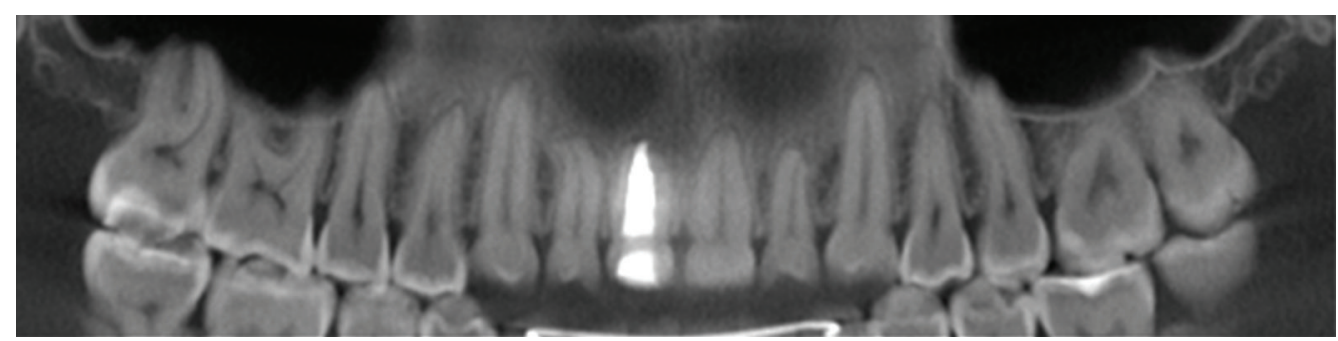

(a)

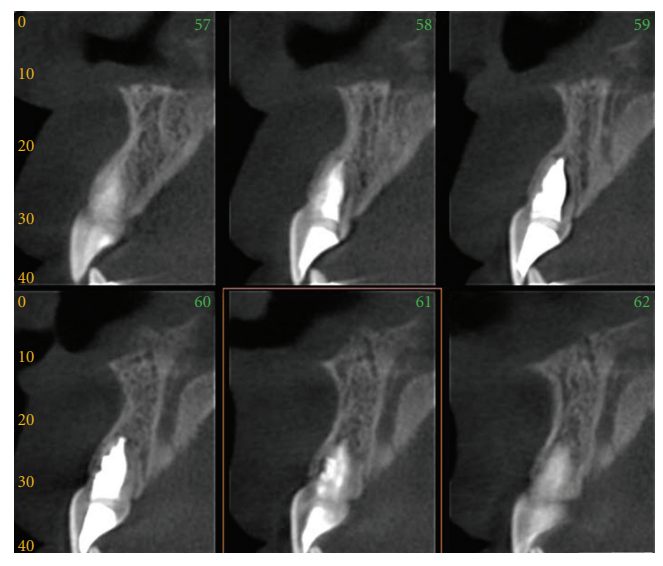

(b)

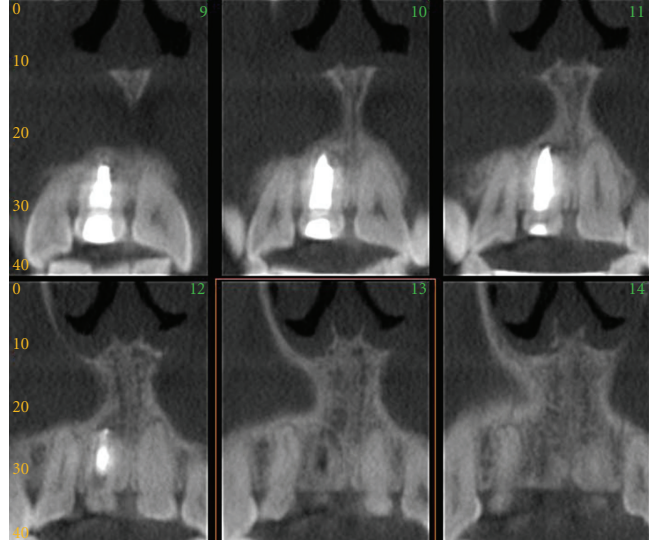

(c)

FIGURE 15: Replacement external resorption associated with root canal filled right maxillary central incisor. An oblique multiplanar reformatted "panoramic" image (a) shows the dentition with minimal restorations and a single root canal filled maxillary right central incisor; note that the obturation is large in relation to the width of the adjacent left maxillary central suggesting endodontic treatment at an early age. Sequential $1 \mathrm{~mm}$ cross-sectional (b) and parasagittal (c) images show bone trabecular-like replacement of the superior and palatal aspects of the root indicative of replacement resorption. Initial management consisted of conventional endodontic treatment. Because of the questionable long-term prognosis of the apical resorptive lesions, periodic CBCT imaging is recommended with a view towards surgical revision therapy consisting of apicoectomy and retrograde root canal treatment (data acquired on an iCAT, Imaging Sciences International, Hatfield, PA USA at $0.4 \mathrm{~mm}$ resolution and reformatted using InVivo Dental, Anatomage, San Jose, CA).

this may be due to the presence of streaking artifacts from the gutta percha and sealer compromising the quality of those images as regards root filling evaluations.

The utility of CBCT in determining the precise nature of a perforation and the role of this on subsequent treatment has been illustrated by Young (Figure 17) [81].

Endodontic surgery is often complicated in the posterior teeth by their proximity to anatomical structures. The mandibular teeth can be close to the mandibular canal while maxillary molars are often close to the maxillary sinus. CBCT imaging provides several advantages for preoperative treatment planning especially in maxillary posterior teeth with apical pathology [82]. Rigolone et al. [83] first described the value of $\mathrm{CBCT}$ in planning for endodontic surgery. They imaged 43 maxillary first molars on 31 patients referred for retreatment and measured the mean distance of the palatine root from the external vestibular cortex (Mean; $9.73 \mathrm{~mm}$ ) and the frequency that the maxillary sinus lateral recess lays between the roots $(25 \%)$ to evaluate the ability to surgically approach the palatal root of a maxillary molar from a vestibular access as opposed to the more difficult palatal access. They concluded that CBCT may play an important role in optimizing palatine root apicoectomy via directing surgery through vestibular access. The importance of CBCT for apical surgery of teeth adjacent to the maxillary sinus has subsequently been illustrated by Nakata et al. [56] who presented a case report localizing the presence of a periradicular lesion to a specific root and Tsurumachi and Honda [84] who described the use of CBCT in localizing a fractured endodontic instrument protruding into the maxillary sinus prior to periapical surgery. Most recently Low et al. [51] compared the preoperative findings obtained from periapical radiography and CBCT of 2 observers in the diagnosis of posterior maxillary teeth (37 premolars and 37 molars-a total of 156 roots) referred for possible apical surgery. They found that CBCT demonstrated significantly more lesions (34\%) than conventional radiography. They also reported that numerous additional clinically relevant findings were seen significantly more frequently in CBCT images including expansion of lesions into the maxillary sinus, sinus membrane thickening, and missed canals. 


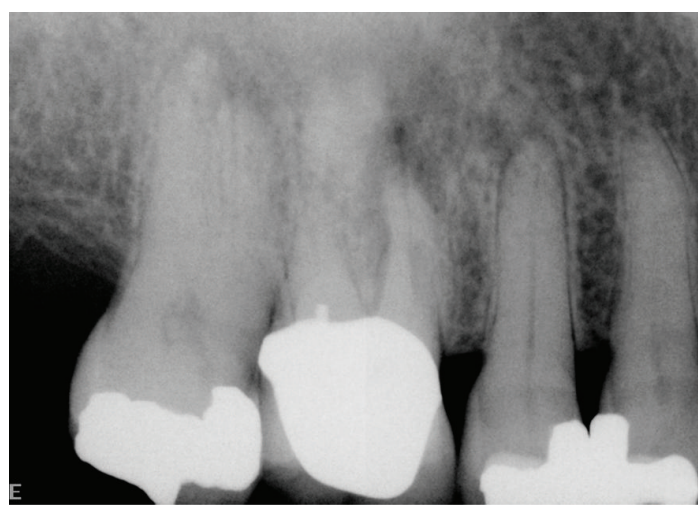

(a)

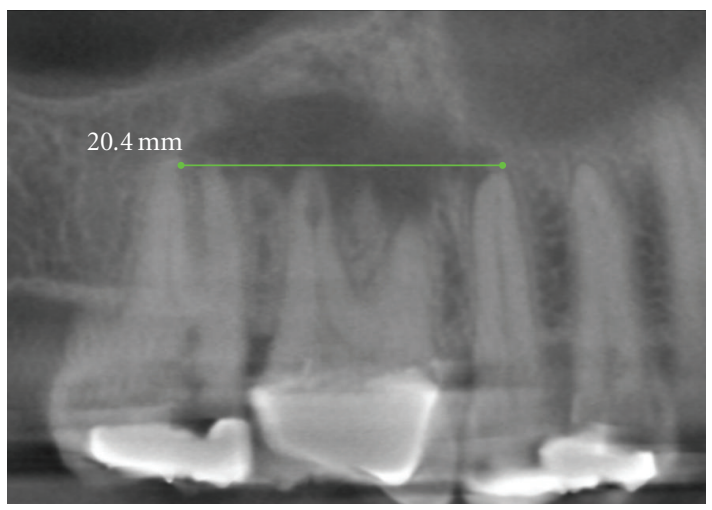

(b)

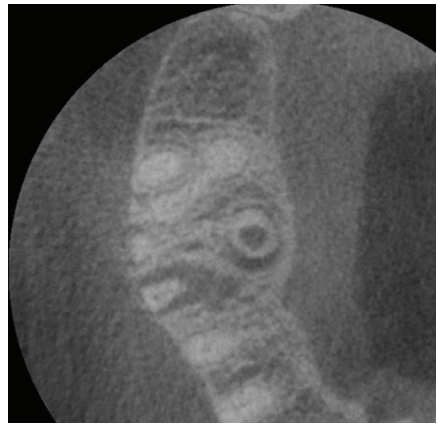

(c)

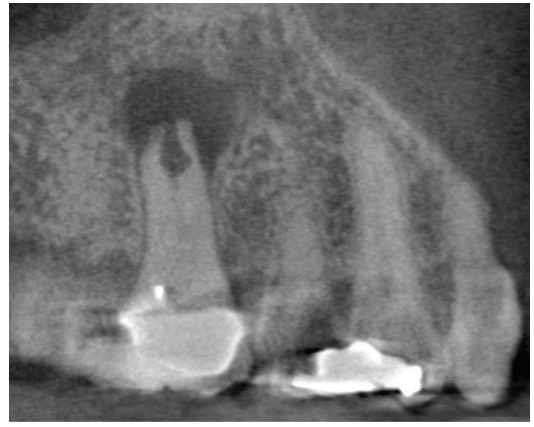

(d)

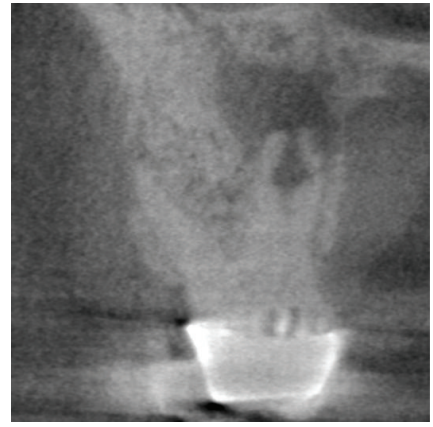

(e)

FIgURE 16: Because two-dimensional imaging suffers from superimposition of anatomic structures, determination of the extent and pathogenesis of periradicular lesions can present diagnostic challenges. This is particularly true of the maxillary posterior region, where the roots of teeth overlap and anatomic structures form complex patterns. A patient presented with discomfort in the maxillary right that extended from the nose to the ear. On clinical examination buccal swelling and induration were present-all teeth tested vital except the maxillary right first molar. A periapical radiograph (a) demonstrated areas of low density at the apices of the maxillary right first and second molars. CBCT images ((b) $10 \mathrm{~mm}$ curved planar, (c) axial, (d) sagittal, (e) cross-sectional) however demonstrated a much more extensive (21.4 mm maximum length) unilocular lesion, centered on the palatal root of the maxillary first molar, and extending anteriorly to the second bicuspid and posteriorly to the second molar. Also note the large internal resorptive lesion at the mid-palatal root of the maxillary first molar, not visible on the periapical radiograph. Biopsy confirmed the lesion to be a periapical granuloma with abscess formation.

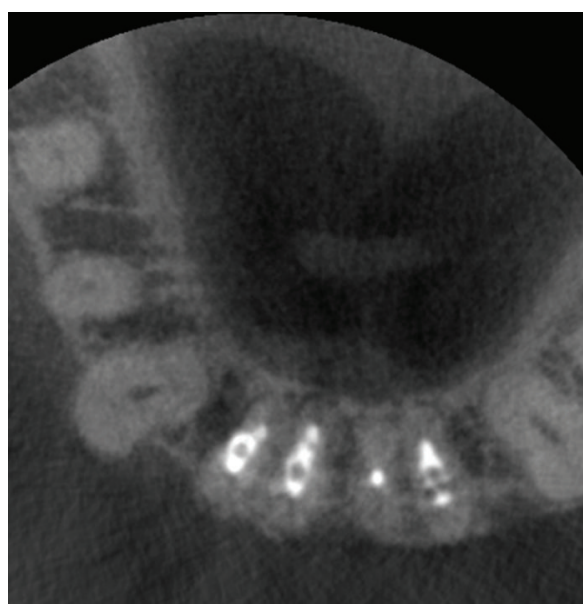

(a)

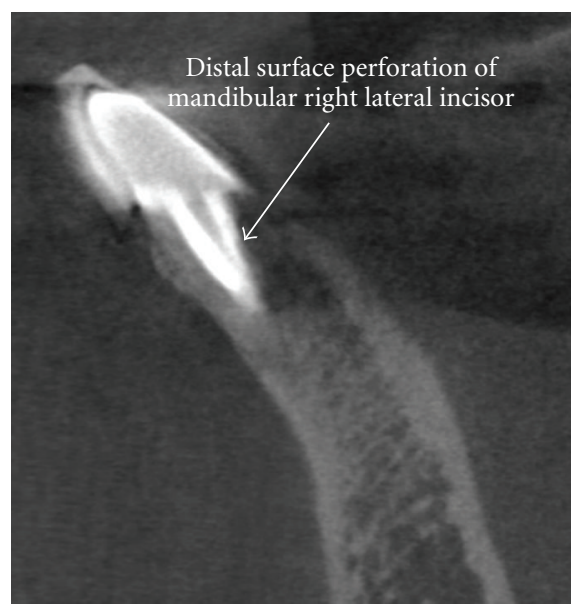

(b)

FIGURE 17: Iatrogenic perforative defects can be difficult to confirm by periapical radiography alone. This patient was referred for evaluation and possible endodontic revision of the mandibular right lateral incisor because of chronic sensitivity to occlusal forces. CBCT images ((a) axial, (b) sagittal) demonstrate a mid-root post perforation. 


\section{Conclusion}

Conventional intraoral radiography provides clinicians with an accessible, cost effective, high-resolution imaging modality that continues to be of value in endodontic therapy. There are, however, specific situations, both pre- and postoperatively, where the understanding of spatial relationships afforded by CBCT facilitates diagnosis and influences treatment. The usefulness of CBCT imaging can no longer be disputed-CBCT is a useful task specific imaging modality and an important technology in comprehensive endodontic evaluation.

\section{Acknowledgments}

The authors gratefully acknowledge the assistance of Lakshmi S. Garladinne-Nethi, B.D.S., M.S., current graduate student in Oral and Maxillofacial Radiology, University of Connecticut, for her assistance in the preliminary stages of the manuscript. Unless otherwise indicated, CBCT data for all figures were acquired on a KODAK 9000 3D at $0.076 \mathrm{~mm}$ resolution and reformatted using KODAK Dental Imaging software v.6.8.6.0 (PracticeWorks, Atlanta, GA).

\section{References}

[1] O. E. Langland and R. P. Langlais, "Early pioneers of oral and maxillofacial radiology," Oral Surgery, Oral Medicine, Oral Pathology, Oral Radiology, and Endodontology, vol. 80, no. 5, pp. 496-511, 1995.

[2] P. H. Jacobsohn and R. J. Fedran, "Making darkness visible: the discovery of X-ray and its introduction to dentistry," The Journal of the American Dental Association, vol. 126, no. 10, pp. 1359-1367, 1995.

[3] A. G. Farman, C. M. Levato, and W. C. Scarfe, "3D X-ray: an update," Inside Dentistry, vol. 3, no. 6, pp. 70-74, 2007.

[4] R. E. Walton, "Diagnostic imaging A. endodontic radiography," in Ingles' Endodontics, J. I. Ingle, L. K. Bakland, and J. C. Baumgartner, Eds., p. 554, BC Decker, Hamilton, Canada, 6th edition, 2008.

[5] V. E. Rushton, K. Horner, and H. V. Worthington, "Screening panoramic radiology of adults in general dental practice: radiological findings," British Dental Journal, vol. 190, no. 9, pp. 495-501, 2001.

[6] H.-G. Gröndahl and S. Huumonen, "Radiographic manifestations of periapical inflammatory lesions," Endodontic Topics, vol. 8, pp. 55-67, 2004.

[7] M. Goldman, A. H. Pearson, and N. Darzenta, "Endodontic success-who's reading the radiograph?" Oral Surgery, Oral Medicine, Oral Pathology, vol. 33, no. 3, pp. 432-437, 1972.

[8] M. Goldman, A. H. Pearson, and N. Darzenta, "Reliability of radiographic interpretations," Oral Surgery Oral Medicine and Oral Pathology, vol. 38, no. 2, pp. 287-293, 1974.

[9] A. G. Farman, "Image guidance: the present future of dental care," Practical Procedures \& Aesthetic Dentistry, vol. 18, no. 6, pp. 342-344, 2006.

[10] A. G. Farman, C. M. Levato, and W. C. Scarfe, "A primer on cone beam computed tomography," Inside Dentistry, vol. 3, pp. 90-92, 2007.
[11] W. C. Scarfe, A. G. Farman, and P. Sukovic, "Clinical applications of cone-beam computed tomography in dental practice," Journal of the Canadian Dental Association, vol. 72, no. 1, pp. 75-80, 2006.

[12] W. C. Scarfe and A. G. Farman, "Cone beam computed tomography: a paradigm shift for clinical dentistry," Australasian Dental Practice, pp. 102-110, 2007.

[13] Y. Hayakawa, T. Sano, P. Sukovic, W. C. Scarfe, and A. G. Farman, "Cone beam computed tomography: a paradigm shift for clinical dentistry," Nippon Dental Review, vol. 65, pp. 125132, 2005.

[14] P. Kursağlu, P. Sukovic, W. C. Scarfe, and A. G. Farman, "Dental Volumetrik Bilgisayarli Tomograti," Akademik Dental, vol. 26, pp. 30-36, 2005.

[15] A. G. Farman, C. Levato, W. C. Scarfe, and D. Chenin, "Cone beam CT trends towards hybrid systems and third party software utilization," Inside Dentistry, vol. 4, no. 9, pp. 102$105,2008$.

[16] J. Valentin, The 2007 Recommendations of the International Commission on Radiological Protection, Publication 103, Annals of the ICRP, vol. 37, 2009.

[17] J. B. Ludlow, L. E. Davies-Ludlow, and S. L. Brooks, "Dosimetry of two extraoral direct digital imaging devices: NewTom cone beam CT and Orthophos Plus DS panoramic unit," Dentomaxillofacial Radiology, vol. 32, no. 4, pp. 229-234, 2003.

[18] F. Gijbels, G. Sanderink, J. Wyatt, J. Van Dam, B. Nowak, and R. Jacobs, "Radiation doses of indirect and direct digital cephalometric radiography," British Dental Journal, vol. 197, no. 3, pp. 149-152, 2004.

[19] J. A. Roberts, N. A. Drage, J. Davies, and D. W. Thomas, "Effective dose from cone beam CT examinations in dentistry," British Journal of Radiology, vol. 82, no. 973, pp. 35-40, 2009.

[20] J. B. Ludlow, L. E. Davies-Ludlow, S. L. Brooks, and W. B. Howerton, "Dosimetry of 3 CBCT devices for oral and maxillofacial radiology: CB Mercuray, NewTom 3G and iCAT," Dentomaxillofacial Radiology, vol. 35, no. 4, pp. 219226, 2006.

[21] E. Coppenrath, F. Draenert, U. Lechel, et al., "Cross-sectional imaging in dentomaxillofacial diagnostics: dose comparison of dental MSCT and NewTom 9000 DVT," RöFo: Fortschritte auf dem Gebiet der Röntgenstrahlen und der Bildgebenden Verfahren, vol. 180, no. 5, pp. 396-401, 2008.

[22] E. Hirsch, U. Wolf, F. Heinicke, and M. A. G. Silva, "Dosimetry of the cone beam computed tomography Veraviewepocs 3D compared with the 3D Accuitomo in different fields of view," Dentomaxillofacial Radiology, vol. 37, no. 5, pp. 268-273, 2008.

[23] S. Lofthag-Hansen, A. Thilander-Klang, A. Ekestubbe, E. Helmrot, and K. Grōndahl, "Calculating effective dose on a cone beam computed tomography device: 3D Accuitomo and 3D Accuitomo FPD," Dentomaxillofacial Radiology, vol. 37, no. 2, pp. 72-79, 2008.

[24] M. Loubele, R. Bogaerts, E. Van Dijck, et al., "Comparison between effective radiation dose of CBCT and MSCT scanners for dentomaxillofacial applications," European Journal of Radiology, vol. 71, no. 3, pp. 461-468, 2009.

[25] J. B. Ludlow and M. Ivanovic, "Comparative dosimetry of dental CBCT devices and 64-slice CT for oral and maxillofacial radiology," Oral Surgery, Oral Medicine, Oral Pathology, Oral Radiology, and Endodontology, vol. 106, no. 1, pp. 930-938, 2008.

[26] T. Okano, Y. Harata, Y. Sugihara, et al., "Absorbed and effective doses from cone beam volumetric imaging for implant planning," Dentomaxillofacial Radiology, vol. 38, no. 2, pp. 79$85,2009$. 
[27] J. M. Palomo, P. S. Rao, and M. G. Hans, "Influence of CBCT exposure conditions on radiation dose," Oral Surgery, Oral Medicine, Oral Pathology, Oral Radiology, and Endodontology, vol. 105, no. 6, pp. 773-782, 2008.

[28] M. A. G. Silva, U. Wolf, F. Heinicke, A. Bumann, H. Visser, and E. Hirsch, "Cone-beam computed tomography for routine orthodontic treatment planning: a radiation dose evaluation," American Journal of Orthodontics and Dentofacial Orthopedics, vol. 133, no. 5, pp. 640.e1-640.e5, 2008.

[29] M. A. Garcia Silva, U. Wolf, F. Heinicke, K. Gründler, H. Visser, and E. Hirsch, "Effective dosages for recording Veraviewepocs dental panoramic images: analog film, digital, and panoramic scout for CBCT," Oral Surgery, Oral Medicine, Oral Pathology, Oral Radiology, and Endodontology, vol. 106, no. 4, pp. 571577,2008

[30] J. B. Ludlow, "Dosimetry of the Kodak 9000 3D Small FOV CBCT and Panoramic Unit," Oral Surgery, Oral Medicine, Oral Pathology, Oral Radiology, and Endodontology, vol. 107, no. 4, p. e29, 2008.

[31] A. G. Farman and T. T. Farman, "A comparison of 18 different X-ray detectors currently used in dentistry," Oral Surgery, Oral Medicine, Oral Pathology, Oral Radiology, and Endodontology, vol. 99, no. 4, pp. 485-489, 2005.

[32] G. S. Liedke, H. E. D. da Silveira, H. L. D. da Silveira, V. Dutra, and J. A. P. de Figueiredo, "Influence of voxel size in the diagnostic ability of cone beam tomography to evaluate simulated external root resorption," Journal of Endodontics, vol. 35, no. 2, pp. 233-235, 2009.

[33] M. Bauman, The effect of cone beam computed tomography voxel resolution on the detection of canals in the mesiobuccal roots of permanent maxillary first molars, M.S. thesis, University of Louisville School of Dentistry, Louisville, Ky, USA, 2009.

[34] W. C. Scarfe and A. G. Farman, "What is cone-beam CT and how does it work?" Dental Clinics of North America, vol. 52, no. 4, pp. 707-730, 2008.

[35] SEDENTEXCT, "Radiation protection: cone beam CT for dental and maxillofacial radiology," Provisional guidelines, v1.1, May 2009.

[36] F. J. Vertucci, "Root canal anatomy of the human permanent teeth," Oral Surgery Oral Medicine and Oral Pathology, vol. 58, no. 5, pp. 589-599, 1984.

[37] F. Pineda, "Roentgenographic investigation of the mesiobuccal root of the maxillary first molar," Oral Surgery Oral Medicine and Oral Pathology, vol. 36, no. 2, pp. 253-260, 1973.

[38] R. Nance, D. Tyndall, L. G. Levin, and M. Trope, "Identification of root canals in molars by tuned-aperture computed tomography," International Endodontic Journal, vol. 33, no. 4, pp. 392-396, 2000.

[39] R. Ramamurthy, J. P. Scheetz, S. J. Clark, and A. G. Farman, "Effects of imaging system and exposure on accurate detection of the second mesio-buccal canal in maxillary molar teeth," Oral Surgery, Oral Medicine, Oral Pathology, Oral Radiology, and Endodontology, vol. 102, no. 6, pp. 796-802, 2006.

[40] R. Ramamurthy, J. P. Scheetz, S. J. Clark, and A. G. Farman, "Effects of imaging system and exposure on accurate detection of the second mesio-buccal canal in maxillary molar teeth," Oral Surgery, Oral Medicine, Oral Pathology, Oral Radiology, and Endodontology, vol. 102, no. 6, pp. 796-802, 2006.

[41] R. P. Matherne, C. Angelopoulos, J. C. Kulild, and D. Tira, "Use of cone-beam computed tomography to identify root canal systems in vitro," Journal of Endodontics, vol. 34, no. 1, pp. 87 89, 2008.
[42] F. Baratto Filho, S. Zaitter, G. A. Haragushiku, E. A. de Campos, A. Abuabara, and G. M. Correr, "Analysis of the internal anatomy of maxillary first molars by using different methods," Journal of Endodontics, vol. 35, no. 3, pp. 337-342, 2009.

[43] M.-G. Tu, H.-L. Huang, S.-S. Hsue, et al., "Detection of permanent three-rooted mandibular first molars by conebeam computed tomography imaging in taiwanese individuals," Journal of Endodontics, vol. 35, no. 4, pp. 503-507, 2009.

[44] B. M. Cleghorn, W. H. Christie, and C. C. S. Dong, "Anomalous mandibular premolars: a mandibular first premolar with three roots and a mandibular second premolar with a Cshaped canal system," International Endodontic Journal, vol. 41, no. 11, pp. 1005-1014, 2008.

[45] C. Estrela, M. R. Bueno, M. D. Sousa-Neto, and J. D. Pécora, "Method for determination of root curvature radius using cone-beam computed tomography images," Brazilian Dental Journal, vol. 19, no. 2, pp. 114-118, 2008.

[46] S. Lofthag-Hansen, S. Huumonen, K. Gröndahl, and H.-G. Gröndahl, "Limited cone-beam CT and intraoral radiography for the diagnosis of periapical pathology," Oral Surgery, Oral Medicine, Oral Pathology, Oral Radiology, and Endodontology, vol. 103, no. 1, pp. 114-119, 2007.

[47] A. Stavropoulos and A. Wenzel, "Accuracy of cone beam dental CT, intraoral digital and conventional film radiography for the detection of periapical lesions. An ex vivo study in pig jaws," Clinical Oral Investigations, vol. 11, no. 1, pp. 101-106, 2007.

[48] T. Özen, K. Kamburoğlu, A. R. I. Cebeci, S. P. Yüksel, and C. S. Paksoy, "Interpretation of chemically created periapical lesions using 2 different dental cone-beam computerized tomography units, an intraoral digital sensor, and conventional film," Oral Surgery, Oral Medicine, Oral Pathology, Oral Radiology, and Endodontology, vol. 107, no. 3, pp. 426-432, 2009.

[49] C. Estrela, M. R. Bueno, C. R. Leles, B. Azevedo, and J. R. Azevedo, "Accuracy of cone beam computed tomography and panoramic and periapical radiography for detection of apical periodontitis," Journal of Endodontics, vol. 34, no. 3, pp. 273279, 2008

[50] C. Estrela, M. R. Bueno, B. C. Azevedo, J. R. Azevedo, and J. D. Pécora, "A new periapical index based on cone beam computed tomography," Journal of Endodontics, vol. 34, no. 11, pp. 1325-1331, 2008.

[51] K. M. T. Low, K. Dula, W. Bürgin, and T. von Arx, "Comparison of periapical radiography and limited conebeam tomography in posterior maxillary teeth referred for apical surgery," Journal of Endodontics, vol. 34, no. 5, pp. 557$562,2008$.

[52] S. Patel, A. Dawood, F. Mannocci, R. Wilson, and T. Pitt Ford, "Detection of periapical bone defects in human jaws using cone beam computed tomography and intraoral radiography," International Endodontic Journal, vol. 42, no. 6, pp. 507-515, 2009.

[53] E. G. Jorge, M. Tanomaru-Filho, M. Gonçalves, and J. M. G. Tanomaru, "Detection of periapical lesion development by conventional radiography or computed tomography," Oral Surgery, Oral Medicine, Oral Pathology, Oral Radiology, and Endodontology, vol. 106, no. 1, pp. e56-e61, 2008.

[54] T. P. Cotton, T. M. Geisler, D. T. Holden, S. A. Schwartz, and W. G. Schindler, "Endodontic applications of cone-beam volumetric tomography," Journal of Endodontics, vol. 33, no. 9, pp. 1121-1132, 2007. 
[55] S. Patel, A. Dawood, T. Pitt Ford, and E. Whaites, "The potential applications of cone beam computed tomography in the management of endodontic problems," International Endodontic Journal, vol. 40, no. 10, pp. 818-830, 2007.

[56] K. Nakata, M. Naitoh, M. Izumi, K. Inamoto, E. Ariji, and H. Nakamura, "Effectiveness of dental computed tomography in diagnostic imaging of periradicular lesion of each root of a multirooted tooth: a case report," Journal of Endodontics, vol. 32 , no. 6, pp. 583-587, 2006.

[57] J. O. Andreasen and F. M. Andreasen, "Classification, etiology and epidemiology," in Textbook and Color Atlas of Traumatic Injuries to the Teeth, J. O. Andreasen and F. M. Andreasen, Eds., pp. 151-216, Munksgaard, Copenhagen, Denmark, 3rd edition, 1994.

[58] M. Cvek, G. Tsilingaridis, and J. O. Andreasen, "Survival of 534 incisors after intra-alveolar root fracture in patients aged 7-17 years," Dental Traumatology, vol. 24, no. 4, pp. 379-387, 2008.

[59] D. A. Tyndall and S. Rathore, "Cone-beam CT diagnostic applications: caries, periodontal bone assessment, and endodontic applications," Dental Clinics of North America, vol. 52, no. 4, pp. 825-841, 2008.

[60] N. Cohenca, J. H. Simon, R. Roges, Y. Morag, and J. M. Malfaz, "Clinical indications for digital imaging in dento-alveolar trauma-part 1: traumatic injuries," Dental Traumatology, vol. 23, no. 2, pp. 95-104, 2007.

[61] D. Ilgüy, M. Ilgüy, E. Fisekcioglu, and G. Bayirli, “Detection of jaw and root fractures using cone beam computed tomography: a case report," Dentomaxillofacial Radiology, vol. 38, no. 3, pp. 169-173, 2009.

[62] S. Patel, "New dimensions in endodontic imaging-part 2: cone beam computed tomography," International Endodontic Journal, vol. 42, no. 6, pp. 463-475, 2009.

[63] B. Hassan, M. E. Metska, A. R. Ozok, P. van der Stelt, and P. R. Wesselink, "Detection of vertical root fractures in endodontically treated teeth by a cone beam computed tomography scan," Journal of Endodontics, vol. 35, no. 5, pp. 719-722, 2009.

[64] K. Kamburoğlu, A. R. İlker Cebeci, and H. G. Gröndahl, "Effectiveness of limited cone-beam computed tomography in the detection of horizontal root fracture," Dental Traumatology, vol. 25, no. 3, pp. 256-261, 2009.

[65] R. A. Bernardes, I. G. de Moraes, M. A. Húngaro Duarte, B. C. Azevedo, J. R. de Azevedo, and C. M. Bramante, "Use of conebeam volumetric tomography in the diagnosis of root fractures," Oral Surgery, Oral Medicine, Oral Pathology, Oral Radiology, and Endodontology, vol. 108, no. 2, pp. 270-277, 2009.

[66] E. Kim, K.-D. Kim, B.-D. Roh, Y.-S. Cho, and S.-J. Lee, "Computed tomography as a diagnostic aid for extracanal invasive resorption," Journal of Endodontics, vol. 29, no. 7, pp. 463-465, 2003.

[67] A. Gulsahi, K. Gulsahi, and M. Ungor, "Invasive cervical resorption: clinical and radiological diagnosis and treatment of 3 cases," Oral Surgery, Oral Medicine, Oral Pathology, Oral Radiology, and Endodontology, vol. 103, no. 3, pp. e65-e72, 2007.

[68] H. L. D. da Silveira, H. E. D. Silveira, G. S. Liedke, C. A. Lermen, R. B. Dos Santos, and J. A. P. de Figueiredo, "Diagnostic ability of computed tomography to evaluate external root resorption in vitro," Dentomaxillofacial Radiology, vol. 36, no. 7, pp. 393-396, 2007.

[69] S. Patel and A. Dawood, "The use of cone beam computed tomography in the management of external cervical resorption lesions," International Endodontic Journal, vol. 40, no. 9, pp. 730-737, 2007.
[70] A. Maini, P. Durning, and N. Drage, "Resorption: within or without? The benefit of cone-beam computed tomography when diagnosing a case of an internal/external resorption defect," British Dental Journal, vol. 204, no. 3, pp. 135-137, 2008.

[71] N. Cohenca, J. H. Simon, A. Mathur, and J. M. Malfaz, "Clinical indications for digital imaging in dento-alveolar trauma-part 2: root resorption," Dental Traumatology, vol. 23, no. 2, pp. 105-113, 2007.

[72] S. Patel, S. Kanagasingam, and T. Pitt Ford, "External cervical resorption: a review," Journal of Endodontics, vol. 35, no. 5, pp. 616-625, 2009.

[73] W. Hahn, S. Fricke-Zech, J. Fricke, et al., "Detection and size differentiation of simulated tooth root defects using flat-panel volume computerized tomography (fpVCT)," Oral Surgery, Oral Medicine, Oral Pathology, Oral Radiology, and Endodontology, vol. 107, no. 2, pp. 272-278, 2009.

[74] A. Dudic, C. Giannopoulou, M. Leuzinger, and S. Kiliaridis, "Detection of apical root resorption after orthodontic treatment by using panoramic radiography and cone-beam computed tomography of super-high resolution," American Journal of Orthodontics and Dentofacial Orthopedics, vol. 135, no. 4, pp. 434-437, 2009.

[75] L. Walker, R. Enciso, and J. Mah, "Three-dimensional localization of maxillary canines with cone-beam computed tomography," American Journal of Orthodontics and Dentofacial Orthopedics, vol. 128, no. 4, pp. 418-423, 2005.

[76] D. Liu, W.-L. Zhang, Z. Zhang, Y. Wu, and X. Ma, "Localization of impacted maxillary canines and observation of adjacent incisor resorption with cone-beam computed tomography," Oral Surgery, Oral Medicine, Oral Pathology, Oral Radiology, and Endodontology, vol. 105, no. 1, pp. 91-98, 2008.

[77] S. L. Hechler, "Cone-beam CT: applications in orthodontics," Dental Clinics of North America, vol. 52, no. 4, pp. 809-823, 2008.

[78] K. Gulabivala and L. J. Searson, "Clinical diagnosis of internal resorption: an exception to the rule," International Endodontic Journal, vol. 28, no. 5, pp. 255-260, 1995.

[79] H. M. Pinsky, S. Dyda, R. W. Pinsky, K. A. Misch, and D. Sarment, "Accuracy of three-dimensional measurements using cone-beam CT," Dentomaxillofacial Radiology, vol. 35, no. 6, pp. 410-416, 2006.

[80] E. Soğur, B. G. Baksi, and H.-G. Gröndahl, "Imaging of root canal fillings: a comparison of subjective image quality between limited cone-beam CT, storage phosphor and film radiography," International Endodontic Journal, vol. 40, no. 3, pp. 179-185, 2007.

[81] G. R. Young, "Contemporary management of lateral root perforation diagnosed with the aid of dental computed tomography," Australian Endodontic Journal, vol. 33, no. 3, pp. 112-118, 2007.

[82] S. Patel, A. Dawood, T. Pitt Ford, and E. Whaites, "The potential applications of cone beam computed tomography in the management of endodontic problems," International Endodontic Journal, vol. 40, no. 10, pp. 818-830, 2007.

[83] M. Rigolone, D. Pasqualini, L. Bianchi, E. Berutti, and S. D. Bianchi, "Vestibular surgical access to the palatine root of the superior first molar: "low-dose cone-beam" CT analysis of the pathway and its anatomic variations," Journal of Endodontics, vol. 29, no. 11, pp. 773-775, 2003.

[84] T. Tsurumachi and K. Honda, "A new cone beam computerized tomography system for use in endodontic surgery," International Endodontic Journal, vol. 40, no. 3, pp. 224-232, 2007. 


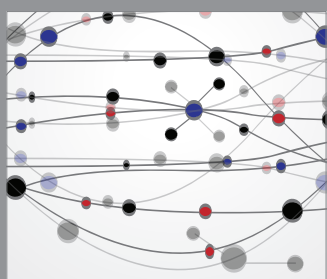

The Scientific World Journal
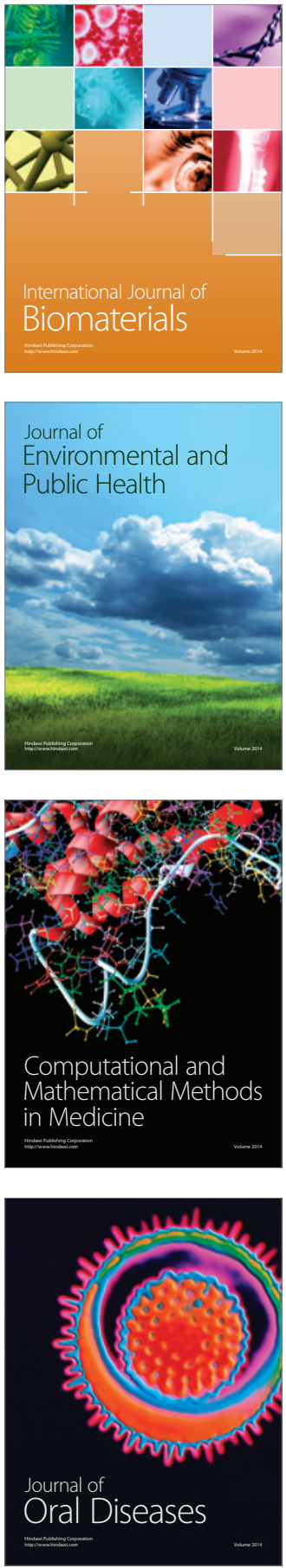
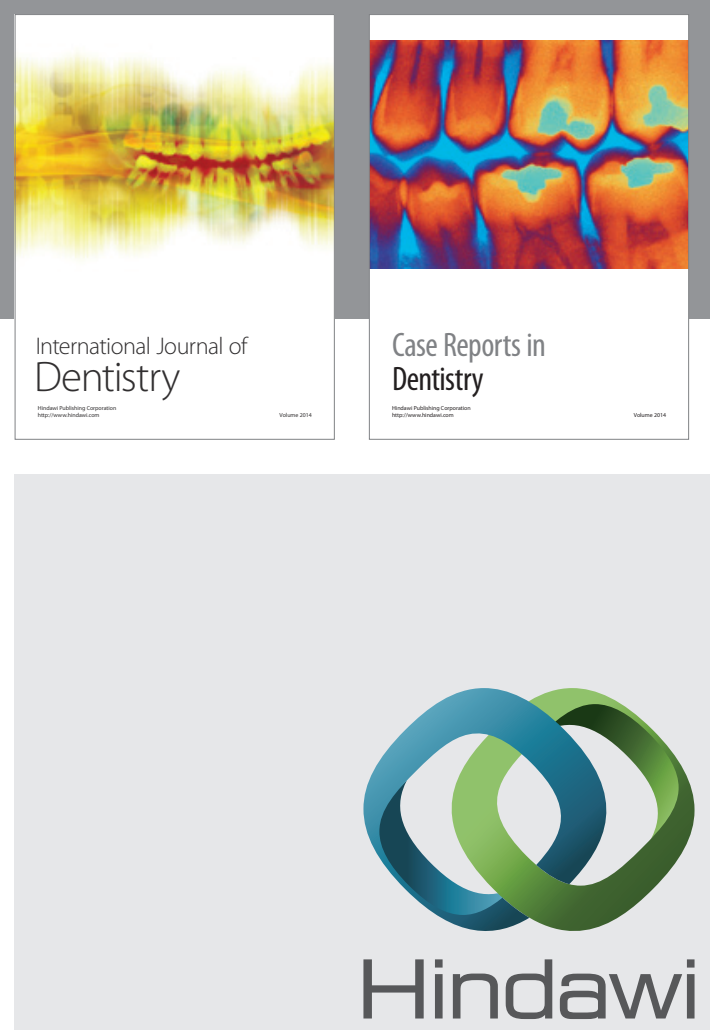

Submit your manuscripts at

http://www.hindawi.com
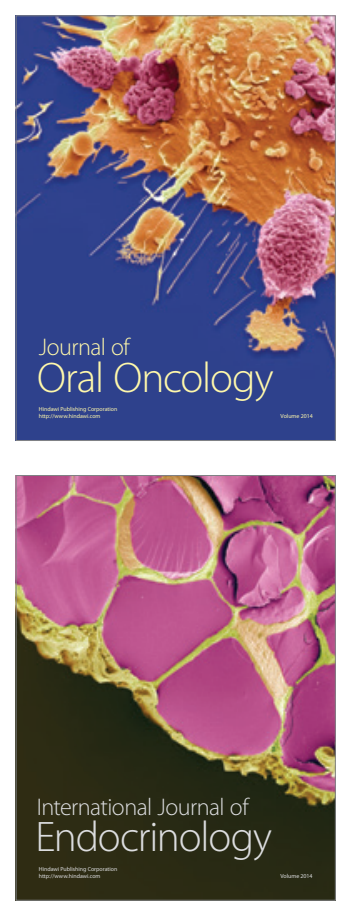
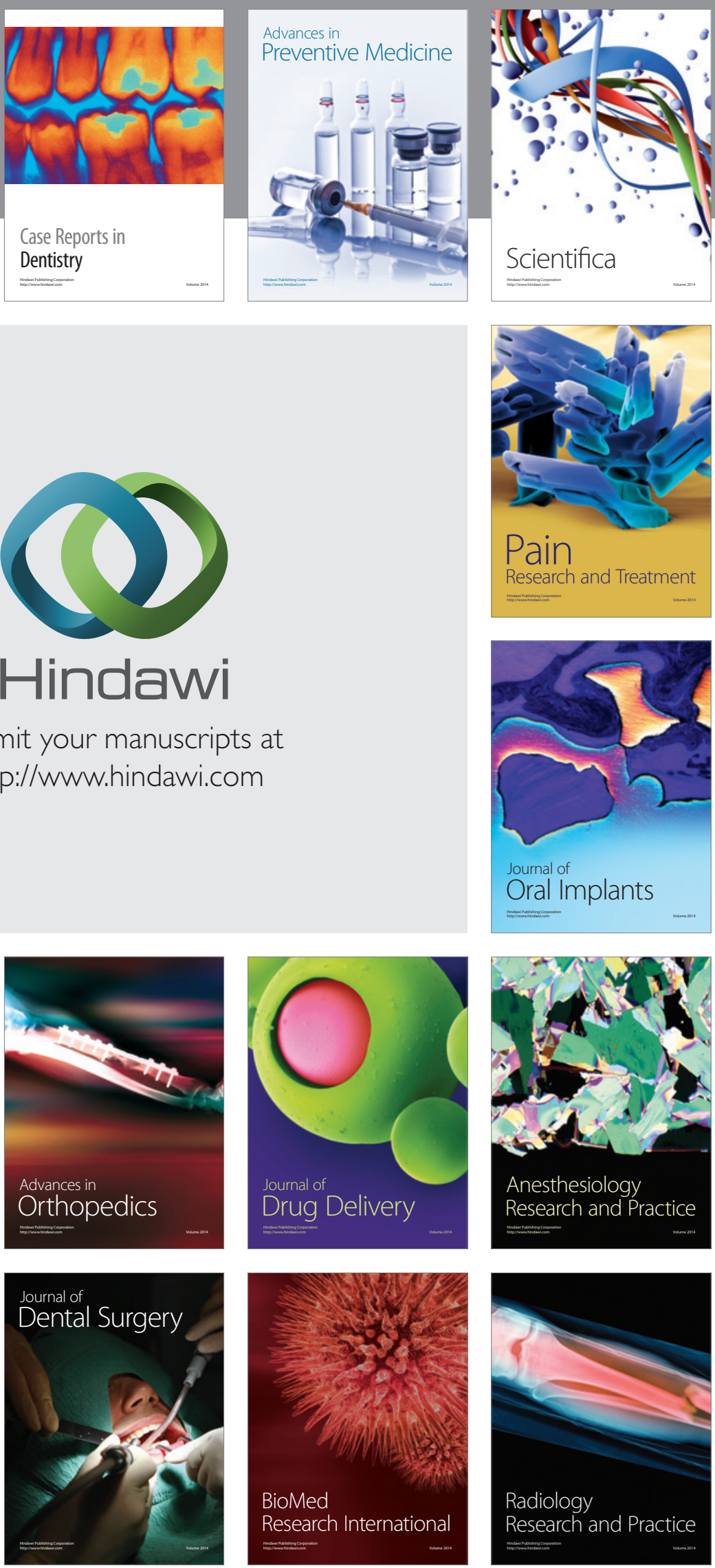